\title{
dspace.vutbr.cz
}

\section{Multimodal Features for Detection of Driver Stress and Fatigue: Review}

NĚMCOVÁ, A.; SVOZILOVÁ, V.; BUCSUHÁZY, K.; SMÍŠEK, R.; MÉZL, M.; HESKO, B.;

BELÁK, M.; BILÍK, M.; MAXERA, P.; SEITL, M.; DOMINIK, T.; SEMELA, M.; ŠUCHA, M.; KOLÁŘ, R.

IEEE Transactions on Intelligent Transportation Systems, pp. 1-20

ISSN: 1558-0016

DOI: https://doi.org/10.1109/TITS.2020.2977762

Accepted manuscript

(C2020 IEEE. Personal use of this material is permitted. Permission from IEEE must be obtained for all other uses, in any current or future media, including reprinting/republishing this material for advertising or promotional purposes, creating new collective works, for resale or redistribution to servers or lists, or reuse of any copyrighted component of this work in other works. NĚMCOVÁ, A.; SVOZILOVÁ, V.; BUCSUHÁZY, K.; SMÍŠEK, R.; MÉZL, M.; HESKO, B.; BELÁK, M.; BILÍK, M.; MAXERA, P.; SEITL, M.; DOMINIK, T.; SEMELA, M.; ŠUCHA, M.; KOLÁŘ, R. " Multimodal Features for Detection of Driver Stress and Fatigue: Review ", IEEE Transactions on Intelligent Transportation Systems, 2020. DOI: 10.1109/TITS.2020.2977762. Final version is available at https://ieeexplore.ieee.org/document/9031734 


\title{
Multimodal features for detection of driver stress and fatigue: review
}

\author{
Andrea Němcová, Veronika Svozilová, Kateřina Bucsuházy, Radovan Smíšek, Martin Mézl, Branislav \\ Hesko, Michal Belák, Martin Bilík, Pavel Maxera, Martin Seitl, Tomáš Dominik, Marek Semela, \\ Matúš Šucha, and Radim Kolář
}

\begin{abstract}
Driver fatigue and stress significantly contribute to higher number of car accidents worldwide. Although, different detection approaches have been already commercialized and used by car producers (and third party companies), research activities in this field are still needed in order to increase the reliability of these alert systems. Also, in the context of automated driving, the driver mental state assessment will be an important part of cars in future. This paper presents state-of-the-art review of different approaches for driver fatigue and stress detection and evaluation. We describe in details various signals (biological, car and video) and derived features used for these tasks and we discuss their relevance and advantages. In order to make this review complete, we also describe different datasets, acquisition systems and experiment scenarios.
\end{abstract}

Index Terms-driver fatigue, driver stress, traffic accident, physiological signals, multimodal features

\section{INTRODUCTION}

E VERY year, more than million injury car accidents happen and more than 25 thousands of people die on European roads [1], [2]. The World Health Organization (WHO) states, that in 2016 (the newest available data) 1.35 million people worldwide died during traffic accidents [3] and 20-50 million people are injured each year [4]. An outlook for the future is not optimistic - traffic injuries will be more common cause of death by 2030 (now it occupies the $8^{\text {th }}$ place and will move up on the $7^{\text {th }}$ place) [3], [5]. Fatigue, drowsiness and sleepiness caused between $0.6-22 \%$ of all injury crashes according to Road Safety Annual Report 2017 [6] published by Organisation for Economic Co-operation and Development (OECD). The percentage varied depending on the country and methodology (e.g. accident analysis, survey) or used database (e.g. official police statistics, in-depth accident studies). The percentage of fatal crashes caused by fatigue can reach up to $30 \%$. Reported percentage differs state to state, because it can be difficult to

This work was supported by the Technology Agency of the Czech Republic, project number TL01000216.

A. Němcová, V. Svozilová, R. Smíšek, M. Mézl B. Hesko and R. Kolář are with the Department of Biomedical Engineering, Faculty of Electrical Engineering and Communication, Brno University of Technology, Technická 12, 616 00, Brno, Czech Republic (e-mails: nemcovaa, svozilova, smisek, mezl, hesko, kolarr @feec.vutbr.cz).

K. Bucsuházy, M. Belák, M. Bilík, P. Maxera and M. Semela are with the Department of Traffic Accident Analysis, Institute of Forensic Engineering, (C) 2020 IEEE.Personal use of this material is permitted. Permission from IEEE must be obtained for all other uses, in any current or future media, including reprinting/republishing this material for advertising or promotional purposes,creating new collective works, for resale or redistribution to servers or lists, or reuse of any copyrighted component of this work in other works. figure out whether fatigue played role in an accident. Nevertheless, these numbers can be underestimated. In [6] there is noted that fatigue-caused crashes are mostly single-car crashes. With accidents, socio-economic costs (including e.g. rehabilitation, healthcare, material damages, lost productivity compensation) of 120 billion EUR per year are connected [4], [7]. WHO reported that traffic accidents cost most countries $3 \%$ of their gross domestic product.

Fatigue belongs to one of five fatal driving behaviors [8]. Fatigue can be caused by lack of sleep, long-time driving, driving at night, monotonous driving, drugs, health problems, overwork, vibrations, other traffic participants, state of roads, passengers, driving under time pressure, driving in unknown environment [9], [10], [11]. Fatigue is strongly influenced by inter-individual variability [12]. In the context of driver research, a trait called fatigue proneness has been described [13], [14]. Apart from that, several personality-related features and constructs have shown a significant predictable relation to driver fatigue, such as lower vitality, locus of control and anxiousness [15], and aggressiveness [16]. Just like personality traits, individual states and moods are also associated with the onset of driver fatigue, e.g. anger, inertia, tension, and hedonic tone [15], [16]. Also, some groups of drivers are at higher risk - people under 25 and over 50 years, shift workers, males, and professional drivers [11]. Fatigue as a general term includes sleepiness [10]. Sleepiness is a need to sleep whereas fatigue is the need to have a rest (not necessarily to sleep) [10]. The irritability, sluggishness, decreasing of concentration and slowness, yawning, heavy eyes, daydreaming, impatience are early signs of fatigue [10], [18]. Fatigue also slows down (prolongs) reaction time, affects judgement, reduces vigilance and causes microsleep [18]. The fatigue on the road can be partially suppressed by stopping and taking a short nap, drinking a coffee or energy drink, airing the car, listening to music [17]. The possibilities of fatigue reduction or modification depend in a certain degree on the source of fatigue

Brno University of Technology, Purkyňova 118, 612 00, Brno, Czech Republic (e-mails: katerina.bucsuhazy, michal.belak, martin.bilik, pavel.maxera, marek.semela @usi.vutbr.cz).

M. Seitl, T. Dominik and M. Sucha are with the Department of Psychology, Faculty of Arts, Palacký University in Olomouc, 771 80, Czech Republic (email: martin.seitl, tomas.dominik01,matus.sucha @upol.cz)

DOI: 10.1109/TITS.2020.2977762.

https://ieeexplore.iee.org/document/9031734 
and its characteristics [20]. If the person is already fatigued, the only proper solution is sleep [18].

Stress while driving could have a number of causes including cognitive, emotional and physiological responses not only to some traffic events but also to the specific life situation. There has been a number of studies shows the role of driver stress as a factor increasing accident risk (e.g. [162], [163], [181], [182], [183], [184]). The hypothesis that stress and related psychological states elevate crash risk was tested by Legree et al. [181]. The results demonstrate strong relationships between emotionally disturbing events and related states with driver at-fault crash status. Emotional stress as a result of divorce in relation to the violation and crash rate was analyzed by McMurray [182]. People involved in divorce process have double accident rate. Increasing accident risk connected with the personal responses to the stressful life events (as marital separation or divorce, child leaving home, partner hospitalization) was proved [183].

According to the theory of allostatics [24], stress can be defined as a complex and at the same time non-specific reaction of the organism including both physical expressions and mental as well as emotional experience. The aim of the reaction is to adapt physiological and behavioral reactions to the requirements of the environment and re-establish the balance (so called allostasis). Stress reaction is related to the activity of autonomous nervous system (sympathicus, parasympathicus), changes of which can be tracked by biosignals and derived features [21]. Specifically, mental stress is connected to activity of sweat glands [22], heart activity, blood pressure (BP), respiration rate [23] and many others. Driver stress can be caused by many stressors such as: mood changes, biorhythm, fatigue, boredom, disease, drugs, traffic (e.g. busy city [26]), weather, night driving, problems in job/family, workload [21], [27], [9]. In spite of the possibility to introduce a list of the most frequent stressors in drivers or according to the classical theories [28], a high inter-individual variability is typical for the start of the stress reaction [29], [13]. Neuroticism [30], aggressiveness, and dislike of driving [13] are among stable personality features taking part in the start and character of the stress reaction. The inter-individual variability in the stress reaction is also influenced by the subjective importance attributed to the stressor in the context of the given situation as well as the length of the period during which allostatic functions of the brain are activated (so called allostatic load). Consequences of the stress reaction resolved by operational reactions with the purpose of re-establishing the allostasis differ from the consequences of the stress reaction allostatic load of which is accumulated on the background [32]. Stress may negatively impact on decision making, performance, awareness, distance judging, concentration [21], [9]. However, the importance of the non-linear (U-shaped) relation between the impacts of the stressors and the development of negative stress consequences is considered [33]. While both U-tops are related to the so called distress (representing the lack of or the over-stimulation by the stressors), the U-basis is connected to an optimum rate of stimulation called eustress. Characteristics of the complex eustress reaction are considered as positive because they cause e.g. improved brain metabolism [34] or improved immunity and executive functions [35], [36] and can also be considered a kind of biosignals.

The topics related to drivers' fatigue and stress detection are still challenging which confirms number of publications and reviews during last decades, e.g. [9], [11], [17], [37]. Also car manufacturers are producing different cockpit fatigue detection systems and assistive technologies as the road safety is one of the priorities. Fatigue monitoring is also important in specific applications, e.g. transport of dangerous vehicles [19].

This review is aimed at different aspect of driver's fatigue and stress assessment with the focus on features extracted from acquired data. Section II introduces available datasets related to driving and also selected non-driving physiological datasets related to stress or fatigue. Section III describes different types of data - vehicle data, physiological signals and features, and also driver behavior-related data. Experiment scenarios are described in Section IV. Few remarks about method used in mass-produced cars are noted in Section V. Discussion and Conclusion summarize this paper in Sections VI and VII, respectively.

\section{Test Databases}

There is currently no freely available database containing complex driver and vehicle data along with proper annotations of stress and/or fatigue. The ideal database should contain biosignals (ECG, PPG, respiratory signal, EDA, brain activity, body temperature, and blood pressure), vehicle data (utilization of the acceleration and brake pedals, the pressure on acceleration pedal, turning the steering wheel) and stress/fatigue rating. However, there are datasets from different research groups, which contain various physiological signals, videorecordings and vehicle data and are available for other researches in order to stimulate research in this field. Here we briefly describe the datasets which are commonly used for driver's stress and fatigue analysis. Furthermore, stress and fatigue related features can be analyzed also in general dataset, not related to driving. Therefore, we start with description of four databases with data from drivers and continue with seven databases unrelated to driving, but useful for stress/fatigue analysis.

Stress Recognition in Automobile Driver database (DRIVEDB) [38] is available from PhysioNet [39]. This database includes electrocardiogram (ECG), electromyogram (EMG) measured on right trapezius, respiration, and electrodermal activity (EDA) measured on the hand and foot (EDA is sometimes ambiguously referred to as galvanic skin resistance or galvanic skin response, GSR; for the sake of clarity, we will use the term EDA in this text). However, a major limitation of the DRIVEDB is that the stress ratings are not publicly available. The article about this database has 673 citations (September 2019) which indicates a great interest in the database with automobile driver data.

Haouij et al. [40] created a database containing 14 driving datasets from 10 drivers. It includes EDA; skin temperature; heart rate (HR); respiration rate; luminosity; environment 
temperature, pressure and humidity; sound. This database is publicly available. The authors have also annotations related to stress.

Schneegass et al. [41] created a publicly available database of biological signals (EDA, temperature, ECG, derived HR, and heart rate variability (HRV)) and data from smartphone (GPS, brightness level, and acceleration). The data come from 10 drivers. The annotations regarding workload are available as well.

Taylor et al. [42], [43], [44] created The Warwick-JLR Driver Monitoring Dataset focused on different workload effect monitoring. The biological part of the database contains 13 sets of ECG and EDA signals and their derivatives - heart rate, heart rate variability, skin conductance level, frequency of EDA responses and action labels. The vehicle data part contains 8 sets each of 189 signals including steering wheel angle, pedal positions and speed. The headings of the signals are available on request.

The following datasets are not related to drivers, but contain complex data from subjects during stress episodes. These are the Non-EEG (Non-electroencephalographic) Dataset for the Assessment of Neurological Status (Non-EEG) [45], ASCERTAIN Dataset [46], Database for Emotion Analysis using Physiological Signals (DEAP) [47], Multimodal Database for Affect Recognition and Implicit Tagging (MAHNOB-HCI) [48], MEG-Based Multimodal Database for Decoding Affective Physiological Responses (DECAF) [49], Stress Level and Emotional State Assessment Database (SLADE) [50] and Dataset for Affect, Personality and Mood Research on Individuals and Groups (AMIGOS) [51].

The Non-EEG database contains EDA, acceleration, HR, temperature and arterial oxygen level $\left(\mathrm{SpO}_{2}\right)$ from 20 healthy subjects. All of these signals were captured on the wrist. This database contains also the neurological status of all subjects in every moment. The neurological status can be relaxation (20 minutes for each subject), physical stress (5 minutes for each subject), mini-emotional stress (40 seconds for each subject), cognitive stress (3 minutes for each subject) and emotional stress (6 minutes for each subject). This database was used to analyzing multimodal data in studies [52], [53], [54]. Non-EEG database is freely available.

ASCERTAIN Dataset [46] contains EDA, ECG, electroencephalogram (EEG) and facial activity data from 58 subjects. All subject watched 36 videos (mean length 80 seconds) to evoke different emotional states. Emotional selfratings is available from each subjects after each video. Dataset contains also personality scores for the Big 5 Personality traits to examine the impact of personality differences on affect recognition. Subramanian et al. [46] analyzed this database. They predicted emotional self-ratings and the Big 5 Personality traits from measured physiological signals. This database was also used in studies [55], [56]. The ASCERTAIN Dataset is available on request.

DEAP contains GSR, blood volume pressure, respiration, skin temperature, EMG, EOG and EEG. In total, 32 subjects are included. Emotions were induced by watching 40 one-minute videos. This dataset is publicly available [47].
MAHNOB-HCI contains EEG, videos of face and body, eye gaze and audio signal for 27 subjects. Emotions were induced by watching 20 videos. The database is available to the academic community [48].

DECAF contains magnetoencephalogram (MEG), nearinfra-red (NIR) facial videos, EOG, ECG and EMG. In total, 30 subjects are included. Emotions were induced by watching 40 one-minute videos and 36 movie clips. The database is available on request [49].

SLADE contains EEG, ECG, skin temperature, and GSR. Emotions were induced by watching one-minute videos [50]. This dataset is not publicly available.

AMIGOS contains EEG, ECG, GSR, and full-body and depth videos for 40 subjects. Emotions were induced by watching 16 short videos and 4 long videos. The dataset is publicly available [51].

\section{StRESS AND FAtigue Detection Methods}

Detection and classification of stress and fatigue usually consists of five steps [21], [57].

1. Data recording - in this step, various signals from vehicle behavior (e.g. steering wheel angle, lane deviation), over the most popular physiological signals (e.g. ECG, EMG, EDA) to data of driver behavior (e.g. video record from on-board camera, eye tracker) are measured. These three groups of signals are described in sections 3.1, 3.2 and 3.3 in detail. For acquisition, various mass-produced as well as experimental devices are used as described in section 3.5. The signals can be measured on diverse body parts. Some databases of these signals are available to scientists as well, more details can be found in section 2 .

2. Preprocessing of the signals - usually includes filtration of various types of noises. In [22] it includes also 4-stage algorithm to distinguish between valid and noisy data. Only valid data are used for further analysis.

3. Feature extraction - features can be extracted in various domains (time, frequency, time-frequency) using linear or nonlinear methods. Sometimes also normalization of features is used to reduce inter-driver variance as in [22].

4. Feature selection and reduction - increases the effectivity and accuracy of classification and decreases computation time and energy costs.

5. Classification - is the last step to predict the level of stress or drowsiness of the driver.

These steps are slightly different if deep learning approaches are used (steps 3 to 5 are merged).

Usually, various sensors are used for data collection and thus more features are used for more robust and accurate detection and classification of stress and fatigue levels [9]. On the other hand, such system can be less comfortable for the driver and thus influences the driver's comfort and increases computational time of subsequent processing and analysis. Each parameter has its pros and cons and therefore it is encouraged to use their combination [17].

\section{A. Vehicle Data}

Vehicle movement and vehicle control are commonly used 
indicators for fatigue detection. Steering or lane-keeping measurements are mostly used. Other parameters such as utilization of the acceleration and brake pedals or the pressure on acceleration pedal [37], [58], [179], yaw rate [174], [189] monitoring the road via camera [9], and GPS localization could be also used for driver state monitoring.

Steering behavior is influenced by the driving task characteristics, particularly road infrastructure (e.g. curvature, road quality). Even during driving without stress or fatigue drivers constantly perform small, smooth driving microcorrections. During fatigue the frequency of steering wheel micro-corrections is reduced [59], [60], [61]. A wide variety of steering-based features are used for driving behavior analysis, namely: steering wheel angle (SWA) [190] or movement (SWM) [62], [176], steering wheel pressure [27], steering reversal rate (SRR) [63], [64], [176] and mean and standard deviation of small steering reversal rate [176], frequency of steering error [65], steering exceeding threshold [66] and many more. These features reflect a driver's ability to control the steering wheel (and the car) in a stable manner. For the elimination of lane changes, Otmani et al. [67] used as a SWM indicator only angles between $0.5^{\circ}$ and $5^{\circ}$. In [66] an increase of SWM amplitude occurred as a function of the time-on-task effect, the frequency of smaller SWM (from $1^{\circ}$ to $5^{\circ}$ ) decreases significantly over time $(\mathrm{P}<0.001)$ and the frequency of large SWM ranging from $6^{\circ}$ to $10^{\circ}$ increases $(\mathrm{P}<0.001)$. These results show that frequency of large SWM is suitable for fatigue detection. Using SWA it was possible to detect drowsiness at least $6 \mathrm{~s}$ prior to a fatigue-induced lane departure [177]. Desmond et al. [68] described that fatigue influences steering performance and lateral position on straight road sections much more than in curved road sections. Bekiaris et al. [173] also stated that in Daimler Chrysler there was tested an algorithm for driver drowsiness detection using longitudinal speed data, lateral position and SWA. The algorithm was validated in field and simulator studies. Dingus et al. [189] proved that YAWMEAN (mean yaw deviation calculated over a threeminute interval) and YAWVAR (yaw deviation variance calculated over a three-minute interval) are affected by driver fatigue and could be used as an indicator of fatigue detection. During drowsy driving the yaw rate increases or decreases by more than $2,5^{\circ} / \mathrm{s}^{2}$ [185]. Li et al. [186] verified in real road driving test, that fatigue identification using SWA and yaw angle time series has higher robustness and reliability.

Especially large speed variations - excessive or insufficient speed according to the given speed limit and running-off-road incidents were defined as indices for occurring drowsiness in a Campagne et al. [187] driving study.

Lane deviation of the vehicle is widely monitored and used as a variable for fatigue analysis (e.g. [58], [59], [63], [65], [66], [69], [70]). Standard deviation of lane position (SDLP) can reflect a driver's ability to maintain driving at a safe position to avoid unintentional lane departure or lane crossing. Attwood et al. [188] use combination of lane position median/range and accelerator position reversal for a multivariate prediction model of driver fatigue. In spite of relative easiness of SDLP measurement and evaluation, there are some difficulties, which make this feature unreliable. As stated in [71], [72] SDLP or lane crossing could be also influenced by alcohol or distraction, which is the main disadvantage of these indicators. Sahayadhas et al. [37] summarize that many studies stated that vehiclebased only measures should not be used as a reliable fatigue predictor. Zhang et al. [73] confirmed that lane position and steering features are inconsistent. Krajewski et al. [74] describe large inter- and intra-individual differences in fatigued driving patterns, based on literature review.

Reliability of lane position data is also dependent on the lane edge marking detection accuracy, which could be influenced by weather such as rain or snow covering. The detection system could also fail due to poor quality or inconsistency of lane markings. The value of these indicators could be also influenced by road geometry.

As evidenced from the AWAKE project [173] - the most promising approach is the combination of physiological and behavioral (traffic task related) parameters. The hypovigilance diagnosis module for analysis of fatigue in real-time is based on combination of vehicle data (lane tracker, steering wheel, gas/brake) and driver characteristics (eyelid, steering grip). The big advantage of using vehicle data is the contactless detection and absence of driver discomfort. On the opposite side there is the influence of vehicle type and weather/driving condition [174].

\section{B. Physiological Features}

Physiological features are the most important ones, because they are robust, reliable and directly connected with the physical and psychical state of the driver [9]. Moreover, the acquisition is not directly disturbed by artefacts due to the changing weather conditions or lighting [9] unlike camerabased ones.

The sensors which are used for sensing of physiological signals should be as much comfortable as possible [57]. They should be noninvasive of course. Some sensors can be integrated in steering wheel or seat [75]. The sensors should not influence or limit the behavior of the driver. The stress event manifests in the physiological signal with some delay depending on the measured signal [57]. These delays are insignificant with respect to overall fatigue or stress detection system but can be significant in some critical situations. Furthermore, some fluctuations of feature values are not necessarily connected with stress [57]. They can be connected with emotions, and other physical or psychical states of the driver [58]. It is favorable to combine more physiological measures because some of them (e.g. EDA) vary among people.

In the next subsections we shortly describe physiological features based on (1) heart rate, (2) photoplethysmography and electrocardiography, (3) respiration, (4) electrodermal activity, (5) brain activity, (6) body temperature, and (7) blood pressure.

\section{1) Heart Rate}

It has been shown elsewhere that HR increases during stress [26]. HRV signal is usually obtained from ECG signal using filtering at the preprocessing stage followed by QRS detection 
[26], [21], [57]. Advanced processing is also used, e.g. integral pulse frequency modulation model [77] with time varying threshold and the smoothed pseudo Wigner-Ville distribution (details are in [78]). Besides ECG, the HR and HRV signal can be also obtained from photoplethysmogram (PPG) [79], [80]. Photoplethysmography can be applied in non-contact manner (based on digital cameras) or a contact manner (usually finger or earlobe sensor). In case of PPG signal, preprocessing is necessary as well and typically includes filtering, squaring and differentiation [80]. Thereafter, PPG peaks are detected [80]. HRV features are extracted from HRV signal in various domains (time, frequency, time-frequency) using linear or nonlinear methods [21], [27].

\section{a) Time Domain HRV Analysis}

The statistical time domain features have been proved to be suitable for stress detection [79]. The most relevant features are: maximum of RRI (RR interval); minimum of RRI; median of RRI; mean of RRI; HR mean; HR standard deviation (STD); STD of the RR (SDNN) - two variants are used: (i) SDNN index (SDNNi) where STD is calculated from RR intervals in 5-min segments and then mean STD is calculated, and (ii) SDANN where mean RRI in each segment is calculated at first and then one STD is computed; root mean square of successive differences of the RRI (RMSSD); the number of successive differences greater than $50 \mathrm{~ms}$ (NN50); the percentage of total intervals that successively differ by more than $50 \mathrm{~ms}$ (pNN50); the percentage of total intervals that successively differ by more than $20 \mathrm{~ms}$ (pNN20); difference between maximal and minimal RRI; and median absolute deviation [26], [81], [82], [21], [22], [77], [79].

The group of geometrical features includes HRV triangular index and triangular interpolation of RR interval histogram (TINN) [21]. In [57], Heart Rate Variation from Baseline $(\mathrm{HRvB})$ feature is proposed as a difference between current heart rate and a baseline calculated within averaging window.

\section{b) Frequency Domain Features}

Frequency domain features can be derived from Lomb periodogram [81]. From the power spectra many features, relevant for stress detection, can be extracted. This group covers mainly absolute spectral powers in different frequency bands aVLF (very low frequency band), aLF (low frequency band) and aHF (high frequency band) and TP (total power); percentage of the sum $\mathrm{pLF}$ and $\mathrm{pHF}$; normalized values $\mathrm{nLF}$ and nHF; peak frequencies pVLF, pLF, pHF [26], [27], [81], [82], [21], [22], [77], [79]. Rigas et al. [164] uses ratio of VLF energy to total signal energy, ratio of LF energy to the total signal energy minus VLF energy, ratio of HF to the total signal energy minus VLF energy, LF/HF ratio, and spectrum entropy. HF is connected with parasympathetic activity whereas LF reflects activity of sympathetic nervous system [83]. The spectral centroid is also used in [22]. Different combinations can be used in order to locate the stress period. For example, the value of $\mathrm{LF} / \mathrm{HF}$ feature significantly increases during stress period [26]. De Nadai et al. [27] showed that during driving this ratio also increases near the critical points such as crossroads and traffic lights.

\section{c) Time-frequency Domain Analysis}

Typically wavelet transform (WT) or short time Fourier transform (STFT) are applied on HRV signal and consequently, spectral parameters are extracted. Munla et al. [21] extracted VLF, LF, and HF features.

\section{d) Non-linear Analysis}

This group includes the following advanced features: sample entropy [21]; detrended fluctuation analysis DFA- $\alpha 1$ and DFA$\alpha 2$ [21]; STD of the short-term and long-term RR interval variability (SD1, SD2, respectively) derived from the Poincaré plots [21].

HR and HRV are one of the most significant indicators of stress [27], [57], [76]. The original signal is inexpensive and not difficult to record [75] and can be relatively easily measured inside the cockpit.

\section{2) PPG and ECG non-HR Features}

The features extracted directly from PPG and ECG signals rather than HRV signals, are also used. These are related mainly to magnitude, energy and signal entropy.

In [22], the authors use original PPG with DC (direct current) component to estimate DC amplitude of PPG, and filtered PPG (without DC) to calculate mean of pulse amplitudes, ratio of these two features, STD of pulse amplitudes, STD of amplitudes differences between pulses, difference between maximal and minimal amplitude, mean of time from PPG valley to its peak (rise time), STD of rise time, mean of time from PPG peak to its valley (fall time), STD of fall time, mean of ratio rise/fall time, STD of ratio rise/fall time, PPG signal energy. Also range of frequencies containing most of the energy (bandwidth) and Shannon entropy are calculated, using equation (1) and (2), respectively [22],

$$
\begin{gathered}
\text { bandwidth }=\frac{1}{2 \pi} \sqrt{\frac{\sum_{i=2}^{N}(X(i)-X(i-1))^{2}}{\sum_{i=2}^{N} X(i)^{2}}}, \\
\text { Shannon entropy }=-\sum_{i=1}^{N}\left(X(i) \cdot \log _{2} X(i)\right),
\end{gathered}
$$

where $X(i)$ is the $i$-th sample of PPG signal and $N$ is the length of PPG signal in samples.

Using both PPG and ECG signals, another feature - pulse arrival time (PAT) - can be extracted [79].

Jiang et al. [84] calculated Kolmogorov entropy (level of system chaos) from ECG signal after lifting WT and showed that this entropy decreases with increasing fatigue.

Singh et al. [81] extracted 6 statistical features for stress assessment: mean, energy, time duration, bandwidth, product of time duration and bandwidth, dimensionality; and five features related to morphology: peak height, rise time, fall time, cardiac period and instantaneous HR.

Keshan et al. [85] used 14 features extracted from ECG signal which are based on the ECG signal annotations - average QRS, RR, QQ, SS, QR, RS intervals, and others. These features were used for detection of stress level (3 states - low, medium, 
high stress) with $88.24 \%$ accuracy.

Some of these non-HR features seem to have promising additional discrimination value. Therefore, if PPG or ECG signal is measured, these features should be considered for driver monitoring.

\section{3) Respiratory Features}

Breathing rate or respiratory rate is another significant indicator of stress [57] and drowsiness [58]. For the purpose of breathing rate estimation, contact and non-contact devices can be used.

Devices from contact group such as chest/abdomen belts and temperature nasal probes are generally considered as less comfortable but more precise [58] than non-contact methods based mostly on digital cameras.

Chest/abdomen belts are based on plethysmography principle [58]. Several features can be extracted from breathing rate signal. For example, in studies [38], [86] six parameters were estimated for stress evaluation. In the time domain the mean value and standard deviation of breathing rate could be easily evaluated by analysis of local maxima and minima in the signal. In frequency domain the spectral powers in different frequency bands $(0-0.1 \mathrm{~Hz}, 0.1-0.2 \mathrm{~Hz}$ and $0.3-0.4 \mathrm{~Hz}$. $)$ are promising features for breathing assessment. Several features can be also extracted from inspiration and expiration dynamics. Inspiration and expiration duration, slope of the inspiration and expiration peaks and the angle formed by them were analyzed in connection with stress in study [87].

The camera-based techniques include the preprocessing stage of acquired data using contrast improvement, filtering, image stabilization and elimination of flares from cars and outdoor public lights [58]. Then the respiratory related signal is extracted from region of interest (ROI) and the breathing rate is obtained after STFT as the mean of dominant frequencies [58]. Breathing rate sensing and estimation may be affected by anthropometric parameters, type of breathing (thoracic/abdominal), illumination, and clothing [58]. Thus, it is necessary to adjust the placement of the camera(s).

Respiratory signal has a potential to be used as a source of additional features for stress and fatigue detection. Furthermore, it is possible to extract this signal from video-data, but with limited precision.

\section{4) Electrodermal Activity}

EDA is connected with autonomous nervous system, specifically with sympathicus [88], which influences activity of sweat glands. There exist two types of EDA signals exosomatic and endosomatic [88], [89]. Commonly measured exosomatic is an impedance of the skin caused by sweating; in this case the source of constant current is used and the skin conductance changes are measured as a result of sweating [89]. Endosomatic EDA is measured by $\mathrm{Ag} / \mathrm{AgCl}$ electrodes and in this case the electrical activity of nervous pulses which activate the sweat glands is measured; the skin potentials are constant and the measured current changes [89]. Skin conductance has two components - tonic (Skin Conductance Level, SCL) and phasic (Skin Conductance Response, SCR). SCL is connected with basic activity of sweat glands without any stimuli presented and is characterized by slow changes (from $10 \mathrm{~s}$ to tens of minutes) [89]. SCR changes faster with coming stimuli and lasts for a shorter period (typically $1-5 \mathrm{~s}$ ) [89]. Please note that the same categorization may be applied to skin potential, dividing it to skin potential level (SPL) and skin potential response (SPR); see for example [90].

Different features can be extracted from EDA signal in order to evaluate stress and/or fatigue. Among others, two features were extracted from EDA signal in $10 \mathrm{~s}$ window in [22]: mean and standard deviation for stress, fatigue, drowsiness and normal state distinction. In [76] the EDA signal was used together with temperature and ECG filtered signals for stress detection (not in driver). EDA signal was filtered using Butterworth low pass filter with cut-off frequency of $5 \mathrm{~Hz}$. Then it was separated into tonic and phasic components. Tonic component was obtained as a straight line which in $15 \mathrm{~s}$ window approximates EDA signal with the least-square error. Phasic component was calculated as a difference between filtered EDA and tonic component. From filtered EDA signal, tonic and phasic components several features were calculated, namely: mean, variance, difference between maximum and minimum (range), ratio of range to absolute mean, ratio of standard deviation to mean and thresholds for which $10 \%, 25 \%, 50 \%$, $75 \%$ and $90 \%$ of data values are smaller than these thresholds [76].

In [57] the authors use mean of the first absolute differences (MFAD) computed from EDA as in (3):

$$
M F A D(t)=\frac{1}{M} \sum_{k=1}^{k=M}\left|e d a_{t}(k+1)-e d a_{t}(k)\right|,
$$

where $M$ is the size of the segment (500 samples). This signal is together with ECG used for stress detection in drivers.

Affanni et al. [88] use endosomatic EDA as a single biosignal to reveal stress events. For this purpose, the adaptive filtration is done at first, then the Smooth Nonlinear Energy Operator (SNEO) was applied and this SNEO signal was used for stress event detection via thresholding.

Taylor et al. [44] extracted two EDA features for workload evaluation - absolute value of the signal and number of spikes in the signal (frequency of EDA responses).

Singh et al. [81] extracted six statistical features: mean, energy, time duration, bandwidth, product of time duration and bandwidth, dimensionality; and eight morphological features: peak rise time, peak amplitude, half-recovery time (time from the occurrence of the EDA peak to its half height), peak energy, average rise rate, average decay rate, percentage decay, number of EDA peaks (details are in [81]).

EDA signal can be measured on feet and hands [9]. Measuring from wrist as reported in [22] may not be sensitive enough. Furthermore, EDA is sensitive to ambient temperature [17], which limits its application. Also, the hand movements (if measured on the wrist) [88] limit its application together with lagged response after the stimulus [75]. 


\section{5) Brain Activity}

It has been shown that specific EEG features are associated with driver's fatigue or stress and several approaches of EEG analysis have been developed over the past 15 years. Both, stress and fatigue are investigated with help of EEG signals.

Borghini et al. [91] have evaluated EEG activities during a monotonous driving session in delta $(0.5-3 \mathrm{~Hz})$, theta $(4-7 \mathrm{~Hz})$, alpha $(8-12 \mathrm{~Hz})$ and beta $(13-30 \mathrm{~Hz})$ bands. Delta and theta activities proved to be stable over entire driving session. Slight decrease in alpha activity and a significant decrease in beta activity $(\mathrm{p}<0.05)$ were observed. All these results, especially a significant decrease in beta activity, point to driver fatigue [91].

Simon et al. [92] have investigated EEG alpha spindles, defined as short narrowband bursts in alpha band, to assess driver fatigue under real driving conditions. Their algorithm was tested on simulated data and then this method was applied to real data acquired while driving in real traffic. Their results were compared with the performance of traditional EEG fatigue measures (i.e. alpha-band power). They found out that EEG alpha spindle parameters increase both fatigue detection sensitivity and specificity. Furthermore, alpha spindles are superior to EEG band power measures for assessing driver fatigue under real traffic conditions.

In a study published in [93], authors measured 16-channel EEG signals, which were transformed into three spectral bands (theta, alpha and beta). Then 12 types of energy parameters were estimated. Based on Grey Relational Activity, the number of significant electrodes was reduced using Kernel Principle Component Analysis. The final evaluation model for driver fatigue was established using the regression equation based on the EEG data from two significant electrodes (Fp1 and O1).

Current studies deal with EEG-based driver fatigue classification [94], [95], [96]. Study of Chai et al. [96] is focused on EEG-based driver fatigue classification among fatigue and alert states and its improvement. Their classification is based on autoregressive modeling as the feature extraction algorithm and sparse-deep belief networks (sparse-DBN) as the classification method. Their classification consists of two kinds of measurements, i.e. psychological (brief psychometric questionnaires) and physiological (video measurement of the face, EEG, eyetracking, etc.).

Stress is also associated with specific EEG features as well as fatigue. One of the older non-driver study published by Haak et al. [97] discussed eye blinking artefacts in the brain activity with respect to stress. They correlated eye blink frequency with experienced stress. They observed higher frequency of eye blinks in stressful situation. Nevertheless, recent studies are focused on design and analysis of EEG-based features in order to characterize driver's mental stress or workload.

Car following test was used in [98] in order to discriminate between braking intention and normal driving. Simple time domain features (temporal average) from EEG signals were classified using support vector machine (SVM) and convolutional neural networks (CNN). They achieved averaged (seven participants) recognition of emergency braking intention almost $72 \%$ for both classifiers. An attempt to characterize driving workload by EEG variations during specific tasks (turning left or right, U-turns, rapid acceleration, rapid deceleration, and changing lanes) is presented in [99] on group of 74 drivers in urban environment. Time features extracted from raw EEG signals were used. Halim and Rehan [100] published a study on subjects who underwent driving-related tasks in laboratory conditions. Several EEG features were tested - time domain (EEG average, standard deviation, $1^{\text {st }}$ and $2^{\text {nd }}$ differences etc.) and frequency domain (power in standard spectral bands). The driving-induced stress was detected with $97.95 \%$ accuracy on 50 subjects. A complex experiment was conducted with electrical vehicle, which served as stressors [101]. Various data was acquired including EEG to identify stress from driving electrical vehicle. Information-theoretic framework was proposed to evaluate mutual information between physiological and operational data from car and GPS.

Although acquisition and analysis of EEG is very useful method to describe brain activity (and also stress and fatigue), it is limited to laboratory conditions. In real driving conditions the acquired EEG signals are affected by noise and artefacts, which make them unusable for reliable analysis.

\section{6) Body temperature}

Body temperature is also connected with stress - the temperature decreases with increasing stress, because of worse peripheral perfusion [9]. It can be measured on specific place on the body or using a thermal camera. Using point sensors, body temperature is usually measured on driver's finger [9], forehead or ear [17]. More complex data could be obtained by thermal imaging. The common areas of interest are different regions on human face. The change of the nose temperature in time could be used for the stress evaluation. Engert $e t$ al. [102] proved the correlation between decrease of the nose tip temperature and other physiological parameters (e.g. HR, LH/HF) during the Cold Pressor Test and Trier Social Stress Test. The application for driver's data both from simulator and real traffic was reported by Or and Duffy [103]. Decrease in the nose tip temperature was confirmed for the dataset from simulator.

Anusha et al. [76] extracted seven different thermal features based on evaluation of thermograms of finger and wrist: mean temperature, minimum and maximum of temperature, its standard deviation, difference between maximum and minimum of temperatures (range), ratio of range to absolute mean and ratio of standard deviation to mean. These features were used with features from ECG and EDA (total of 61 features) for detection of psychological stress. The use of physiological signals was proven as a sufficient for stress detection.

Another usage of the thermal images is estimation of specific physiological parameters from small changes in videothermograms. Cardone and Merla [104] reviewed applications for estimation of cardiac pulse, breathing rate, cutaneous blood perfusion and sudomotor response and consequent using of these indirectly estimated physiological parameters in physiological and stress monitoring.

The main advantage of temperature monitoring is the possibility of non-contact acquisition. Nevertheless, the main 
disadvantage of the temperature measurement is its sensitivity to ambient temperature [17], particularly in a case of car air conditioning. Furthermore, the thermal imaging is relatively costly solution, due to high price of thermal cameras.

\section{7) Blood Pressure}

Many studies have examined the effect of the fatigue or stress on hemodynamic parameters. According to [105], where 142 individuals participated in a study, there was no significant effect of the fatigue on BP between three fatigue level groups. Moreover, research suggested that neither HR is related to the fatigue level. However, even if these simple parameters are not fatigue dependent, stroke index and cardiac index derived from stroke volume and cardiac output are decreasing with increasing fatigue. The same study also tested stress effect on the HR and BP, concluding dependency of these parameters on the stress factor. In another study [106], chronic fatigue syndrome, which has currently no effective treatment, was examined. The patients suffering from chronic fatigue syndrome exhibited lower BP and also lower mean arterial pressure. Barendregt et al. [107] focused on relating BP with fatigue in patients with primary Sjogren's syndrome (SS). In the group of 125 patients (49 with SS, 44 patients with rheumatoid arthritis and 32 healthy women), no statistic dependency was found between fatigue and BP. Finally, last study [108] examined effect of the fatigue on several physiological, biochemical, vision and psychological markers of 24 city bus drivers. Tests were made before and after $7 \mathrm{~h}$ of driving. This study found a slight dependency of the diastolic BP on the fatigue.

Comparing to the fatigue, stress dependency is much more evident in BP. Because there is no study, which relates the driving-related stress to BP, we present two different studies, to show the usefulness of BP acquisition for stress detection.

In a limited study [109] with 12 females, HRV and BP were examined as a reaction on a stress factor (participant must key in the six digits, which were presented on the screen, during $4 \mathrm{~s}$ ). BP was measured continuously during the experiment, showing a statistically significant dependency. However, stress showed to be correlated with HR more than BP, whereas BP is more influenced by the local changes caused by muscles contractions. One of the largest studies [110] was designed to test whether it is possible to predict hypertension as a result of high BP response to stress factor at young age. The sample was large, counting more than 4100 people. One of the intermediate results consists of proving that each of the three different stress factors (cold pressor, star tracing and video game task) caused measurable change in systolic and diastolic BP.

Because there is not a single type of stress, various stimuli might cause different stress reactions. In [111], researchers studied the effect of three different stress tasks (the cold pressor, a pornographic film, random electric shock) on the systolic and diastolic BP. Moreover, experiment participants were split into two groups, the first had possibility to avoid the stress agent, and the second one had not. Results showed that each of the stress factors ended with increased systolic and diastolic BP. However, systolic BP had larger absolute change and might be more dependent on the type of the stress factor. In one of the last study [112], which was directly connected to the drivers' profession, researchers examined 34 male taxi drivers using a Holter ECG and Holter BP (with 30 minutes period). According to the results, taxi drivers showed higher systolic and diastolic BP while being at work. Afterwards, on the first day-off, both BP dropped $(\mathrm{p}<0.05)$ and slightly increased the next day, which was also non-workday. Authors concluded that long duty taxi driving raised $\mathrm{BP}$ and increased further cardiovascular risk.

From these studies we may conclude that there is no significant dependency of the BP on fatigue, but the stress is connected with an increase of the BP. The rate of an increasing is dependent on the stress type, but in general, all types of stress may be linked to the increase of the BP. However, response on the stress is more easily observable on the HR, with the same increasing mechanism connected with autonomous nervous system. Even if the fatigue cannot be connected with the higher pressure, more complicated hemodynamic parameters can be correlated with fatigue, like stroke index or cardiac index [105].

\section{Driver Behavior}

The methods based on measuring of physical changes are nonintrusive, thus suitable and easily applicable for real driving condition analysis. Most behavioral metrics are measured based on facial expression (such as mouth or eye state analysis) or body movements (especially head or hand movements). For the purpose of driver behavior analysis, accelerometers (ACC) and video based techniques are commonly used. In order to analyze driver fatigue at night, infrared illumination was used in some studies [113].

Driver behavior features based on (1) facial expression, (2) eyetracking, (3) reaction time, and (4) body movements will be presented in this section.

\section{1) Facial Expression}

Facial expression can provide valuable information about driver status, including fatigue and drowsiness. Two main steps of facial expression recognition algorithms are extraction of features related to the face geometry and classification of expressions. In [114] entropy analysis was used for the extraction of salient face regions. Furthermore, Discrete WT (DWT) was performed to divide the input into frequency bands and transfer the fine details of expressions. To further performance improvement, Discrete Cosine Transform (DCT) was applied. Jabon et al. [169] applied a machine learning approach for prediction of minor and major accidents (on driving simulator) using various facial expression-based features merged with data from vehicle dynamic. There are also papers $[170,171]$ where the authors applied facial expression analysis methods on video data from car cockpit, but without relation to stress or fatigue during driving.

Besides parameters of eye behavior currently connected with fatigue analysis, the driver emotional state (including stress and fatigue) could be also estimated by analysis of some selected characteristic points on the face (eye corners, mouth corners or eyebrows). Panda et al. [175] described feature selection for analysis of driver drowsiness using eye movement to detect eye 
opening. Among evaluated methods (Canny Edge, Local Binary Patterns, Gabor Filter Bank, etc.), Histogram of Oriented Gradients was the most accurate one. For the analysis of emotional state e.g. distance from eye to mouth or eyebrows or mouth curvature could be used [120].

Generally, facial expression analysis is recently a hot research topic with various applications. It can be expected that in connection with deep learning approaches, it will provide a valuable tool for driver fatigue and stress detection.

\section{2) Eyetracking}

Nowadays, the majority of eye-tracking methods is based on combination of the video-imaging and corneal reflection techniques. As stated in [121], attaching electrodes and biosignals measuring devices to the drivers for the purpose of fatigue monitoring would not be practical for the vehicle manufacturers, thus video-based eyetracking methods are considered as the only option of fatigue assessing.

Eyetracking methods are commonly used to measure a view direction or eye movements relative to the head and allow monitoring, detecting and evaluating of visual sequences of drivers [122], [123], [124].

Various features are used for fatigue quantification, e.g. percentage of eyes closure (PERCLOS), blinking duration (BD), blinking speed, saccadic movements, pupil diameter, gaze, and slow eye movements [58]. PERCLOS was proposed in 1994 as the proportion of time for which the eyelid remains closed more than $80 \%$ within a predefined time period. It reflects slow eyelid closures rather than blinks. PERCLOS is used very often in driving studies dealing with fatigue detection in real environment as the most valid drowsiness measure (e.g. [119], [121], [125], [126], [127]). As stated in [128], PERCLOS TABLE I

DIVISION OF DRIVER REACTION TIME, DETERMINATION OF VISUAL, PSYCHICAL AND PHYSICAL PARTS ACCORDING TO OLDER AND CONVENTIONAL NOMENCLATURE [133]

\begin{tabular}{|c|c|c|c|}
\hline \multirow{2}{*}{} & \multicolumn{2}{|c|}{ Duration (s) } \\
\cline { 2 - 4 } & $\begin{array}{c}\text { Lower } \\
\text { limit } \\
(2 \%)\end{array}$ & Average & $\begin{array}{c}\text { Upper } \\
\text { limit } \\
(98 \%)\end{array}$ \\
\hline $\begin{array}{l}\text { Visual reaction time of drivers } \\
\text { (variants): }\end{array}$ & & & \\
a) direct view of the critical & 0.00 & 0.00 & 0.00 \\
$\begin{array}{c}\text { bbject } \\
\text { c) view within 5 degrees }\end{array}$ & 0.32 & 0.48 & 0.55 \\
\hline Psychical reaction time & 0.41 & 0.61 & 0.7 \\
\hline $\begin{array}{l}\text { Movement reaction time } \\
\text { Response of vehicle: } \\
\text { brake delay } \\
\text { - braking effect }\end{array}$ & 0.22 & 0.45 & 0.58 \\
\hline $\begin{array}{l}\text { Total response of vehicle } \\
\text { SUM of variants: } \\
\text { a) direct view } \\
\text { b) view within 5 degrees } \\
\text { c) view above 5 degrees }\end{array}$ & 0.15 & 0.19 & 0.21 \\
\hline \hline
\end{tabular}

showed the clearest relationship with performance on a driving simulator compared to a number of other potential drowsiness detection approaches including two EEG algorithms, a head tracker device, and two wearable eye-blink monitors. Bergassa et al. [117] showed high robustness of PERCLOS assessment they obtained a total correct percentage of PERCLOS detection about $93.12 \%$. Dasgubta et al. [180] tested the algorithm for PERCLOS calculation also in nighttime condition. The algorithm was cross-validated using EEG signal. The system was found to be quite robust in terms of speed and accuracy.

Another published parameters used for the fatigue or stress analysis are: PERSAC (percentage of saccadic movement), AECS (average eye closure/open speed) [119], GAZEDIS (gaze spatial distribution over time), BD, BF (blink frequency) [119], PerLPD (percentage of large pupil dilatation), etc. The relation between stress and GAZEDIS, AECS was analyzed in [129] - correlation between stress and GAZEDIS and PerLPD are positive, whereas between stress and AECS it is negative. As stated in [119], features related to the eye opening speed and PERCLOS perform the best potential for fatigue detection. The $\mathrm{BD}$ values are also related to the driver's advanced drowsiness level, but the results are distorted by vertical looks to the dashboard recognized as blinks [119].

Eye tracking is already used in some cars for fatigue/alertness detection (e.g. SmartEye project). It can be expected that it will become a standard approach soon, also due to its relatively low cost. Furthermore, the advanced image processing approaches will probably lead to increase of robustness of this method in the near future.

\section{3) Reaction Time}

Reaction time of driver is one of the most important features describing the driver behavior. Older studies focused on driver fatigue and stress and their connection with prolonged reaction time of driver [66], [130], [131], [132]. According to conventional nomenclature of transport experts, driver reaction time consists of three main parts - visual, psychical and movement reaction time [133]. The first part of reaction time is visual reaction time, which is a time necessary for object (e.g. pedestrian) recognition. This part of reaction time ends at the moment of sharp fixation of the driver's eye on this object $\left(\mathrm{T}_{\mathrm{F}}\right)$, see Fig. 1. Psychical reaction time that ends at the moment of releasing accelerator $\left(\mathrm{T}_{\mathrm{A}}\right)$ follows. Movement reaction time ends at the moment of the first contact between right lower limb and brake pedal $\left(\mathrm{T}_{\mathrm{B}}\right)$. For all of the parts of driver reaction time, reference values were stated and they are used by the experts for decades. With the development of the new technologies and methods (e.g. eyetracking, EEG, EMG) it turns out that conventional division of reaction time could be stated in different way and its tabulated values can be defined directly from acquisition of driver's biosignals as in Table I.

In order to analyze reaction time more precisely, eyetracking methods are combined with electrical potential measurements. In laboratory conditions, the electrical potential measurements (EEG, EMG, ECG, HRV, etc.) are used especially for fatigue detection [134], [135]. These signals are used for verifying or calibrating of alertness systems frequently, typically EEG. 
Recent study [136] refers to combination of vehicle control information (steering wheel pressure) and video capture for monitoring facial state change which has been used to investigate non-alerted driver response during a pre-crash.

Combination of eyetracking and EMG allows different and more comprehensive analysis of reaction time - visual reaction time, time needed to decision and muscle response time. The alternative partition of reaction time was proposed in [137] (Fig. 1). Visual reaction starts and ends at the same moments as visual reaction time (Visual RT) of conventional division mentioned above. The second part is time needed to decision (interval TD). TD starts at the moment of sharp fixation of object appeared in the field of driver's view (interval $T_{F}$ ) and ends at the moment of muscle activation $\left(\mathrm{T}_{\mathrm{EMG}}\right)$. $\mathrm{TD}$ is a time needed to object recognition in the CNS, i.e. time needed to a decision about reaction and style of response. The third part is muscle response time (MRT) which starts at the moment of muscle activation ( $\mathrm{T}_{\mathrm{EMG}}$, mostly musculus tibialis anterior) and ends at the moment of the first contact between right lower limb and brake pedal $\left(\mathrm{T}_{\mathrm{B}}\right)$.

Fig. 1. Reaction time (RT), $\mathrm{T}_{\mathrm{ON}}$ is the moment when the object just appeared in the driver field of vision, $\mathrm{T}_{\mathrm{F}}$ is the moment of sharp fixation of the driver's eye on this object, $\mathrm{T}_{\mathrm{EMG}}$ is the moment of muscle activation (musculus tibialis anterior), $\mathrm{T}_{\mathrm{A}}$ is the moment of releasing accelerator, $\mathrm{T}_{\mathrm{B}}$ is the moment of the first contact between right lower limb and brake pedal [137].

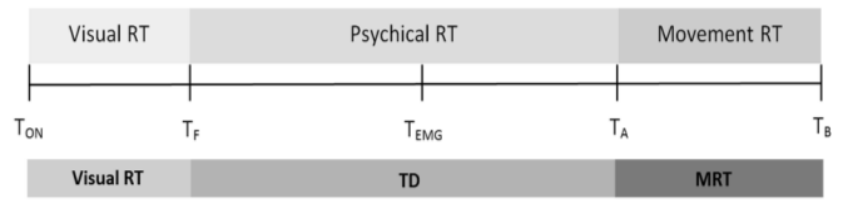

Nowadays, investigation of reaction time is considered very important, because it is connected to driver fatigue - during a drive, fatigue can cause the prolonging reaction time [59]. Therefore, current trend of traffic and transport is focused on the new ways how to measure reaction time and its parts.

\section{4) Body Movements}

The signals related to body movements (head or hand movements) are also possible source of features for fatigue and stress detection. These signals can be measured directly via appropriate sensors (e.g. ACC) or indirectly (e.g. steering wheel motion).

Head movements seem to be an early indicator for sleepiness [119]. As one of the fatigue signs, yawn detection algorithms are used. Reddy et al. [115] used simple segmentation based on thresholding for the yawning detection with detection accuracy rate of $76 \%$. In [116], a system aimed to identify yawning by measuring physical changes occurring in drivers mouth based on circular Hough transform reaches $98 \%$ accuracy.

Nodding is another useful sign of fatigue assessment [117], [118]. During nodding, drivers close their eyes and the head goes down. Bergassa et al. [117], however, demonstrated the worst results in detected percentage of nodding compared to the other parameters such as PERCLOS, eye closure duration, BF or face direction. In [119] the head nodding was calculated from the head pitch angle and exponentially weighted moving variance (EWVAR) and showed relatively small correlation coefficient (-0.32) with sleeping score.

In [22], body movements are sensed by 3-axis ACC and 3axis gyroscope integrated in bracelet. In a preprocessing stage, the ACC signal is filtered using bandpass filter $(0.5-11 \mathrm{~Hz})$, and then all the 3 axes are combined into motion information (MI):

$$
M I=\sqrt{\left(x_{f}^{2}+y_{f}^{2}+z_{f}^{2}\right)}
$$

Signals from gyroscope are combined in the same way [22] and titled as gyro motion information (GMI).

Extracted features are: the mean amplitude of $10 \mathrm{~s}$ MI segment, power of $10 \mathrm{~s}$ MI segment, mean amplitude of $30 \mathrm{~s} \mathrm{MI}$ segment, power of $30 \mathrm{~s}$ MI segment. The same features are extracted from GMI signal. These features are used together with other biosignal-based features as an input to classifier.

The angle of steering wheel motion is also signal suitable for stress [82] and fatigue recognition and can be considered as body movement-related signal. It can be represented by roll orientation, which can be calculated using 9-DOF (degree of freedom) IMU (inertial motion unit). From roll orientation signal several features are calculated: average; standard deviation; variance; median; averaged squared power; root mean square; range difference of max and min [82]. After applying of DFT on difference of roll orientation signal, ORV (orientation rate variability) is obtained. From ORV other features are extracted: sum power spectrum energy; Shannon entropy energy; mean, peak and median power frequency [82]. Two phase-based features are extracted in [82]: percentage of points outside the control eclipse and weighting function outside the control eclipse.

Body movement signals can provide important information about driver behavior and driving style. However, these signals need to be measured in contact way and can be distorted by driving on the rough terrain. Furthermore, similar information can be obtained from video acquired from cockpit.

\section{Summary Table of features and their behavior under stress and fatigue conditions}

Summary of the most common and important features are shown in Table II with the trend of their behavior under stress and fatigue conditions. 
TABLE II

SuMmary TABLE OF FeATURES AND THEIR BEHAVIOR UNDER STRESS AND FATIGUE CONDITIONS

\begin{tabular}{|c|c|c|}
\hline feature & fatigue/stress & $\begin{array}{l}\text { increase/ } \\
\text { decrease }\end{array}$ \\
\hline steering & fatigue [59], [177] & $\downarrow$ \\
\hline lane deviation & fatigue [60], [69] & $\uparrow$ \\
\hline heart rate & $\begin{array}{l}\text { stress [26], [27], [75], [76], [81], [82] } \\
\text { fatigue [17], [75], [89] }\end{array}$ & $\begin{array}{l}\uparrow \\
\downarrow\end{array}$ \\
\hline HRV & \begin{tabular}{|l} 
fatigue [17], [75] \\
stress [75]
\end{tabular} & $\begin{array}{l}\uparrow \\
\downarrow\end{array}$ \\
\hline LF (HRV) & fatigue [17] & $\downarrow$ \\
\hline HF (HRV) & fatigue [17] & $\uparrow$ \\
\hline $\mathrm{LF} / \mathrm{HF}$ ratio & $\begin{array}{l}\text { stress [26], [81] } \\
\text { fatigue [17] } \\
\text { fighting with fatigue [17] }\end{array}$ & $\begin{array}{l}\uparrow \\
\downarrow \\
\uparrow\end{array}$ \\
\hline $\begin{array}{l}\text { Kolmogorov entropy } \\
\text { of ECG }\end{array}$ & fatigue [84] & $\downarrow$ \\
\hline breathing frequency & $\begin{array}{l}\text { stress [27], [81] } \\
\text { fatigue [17] }\end{array}$ & $\begin{array}{l}\uparrow \\
\downarrow\end{array}$ \\
\hline $\begin{array}{l}\text { the slope of the } \\
\text { exhalation curve }\end{array}$ & stress [87] & $\uparrow$ \\
\hline $\begin{array}{l}\text { the slope of the } \\
\text { inhalation curve }\end{array}$ & stress [87] & $\downarrow$ \\
\hline $\begin{array}{l}\text { the angle between the } \\
\text { inhalation and the } \\
\text { exhalation curve }\end{array}$ & stress [87] & $\uparrow$ \\
\hline EDA & $\begin{array}{l}\text { stress [75], [82] } \\
\text { fatigue [17], [75], [89] }\end{array}$ & $\begin{array}{l}\uparrow \\
\downarrow\end{array}$ \\
\hline body temperature & $\begin{array}{l}\text { stress [9] } \\
\text { fatigue [17] }\end{array}$ & $\downarrow$ \\
\hline blood pressure & $\begin{array}{l}\text { stress [105], [111] } \\
\text { fatigue [75] }\end{array}$ & $\begin{array}{l}\uparrow \\
\downarrow\end{array}$ \\
\hline blink duration & fatigue [119], [174] & $\downarrow$ \\
\hline blink frequency & Fatigue [174], stress [119] & $\downarrow$ \\
\hline PERCLOS & fatigue [121], [125], [126], [127] & $\uparrow$ \\
\hline yawning & fatigue [117] & $\uparrow$ \\
\hline nodding & fatigue [117], [178] & $\uparrow$ \\
\hline
\end{tabular}

\section{E. Stress and Fatigue Evaluation (Classification Methods)}

Recently, traditional and deep learning-based approaches are used for detection and classification of drivers' fatigue and stress. The traditional approaches consist of features extraction and classification, while deep learning uses original domain data to find context in this data and use it for classification as a part of this approach. Some recently (years 2018, 2019) published methods are briefly summarized in below paragraphs. Table in Supplemental files shows the diversity of research in this area represented by several examples of published papers - various approaches for stress or fatigue detection (or prediction) together with different signals and features tested on different datasets has been published.

Choi et al. [22] extracted features from PPG, EDA, ACC and gyroscope. After 5 different types of normalization, they obtained altogether 190 features. Therefore, they used two methods for features selection: 1) ANOVA which selected 25 features followed by 2) sequential forward floating selection (SFFS) algorithm. The SVM with radial basis function (RBF) kernel and one of "winner-takes-all" (WTA) and "max-wins voting" (MWV) expansions is used. The expansions enable to classify into more than two classes (stress, fatigue, drowsiness, normal state). The best accuracies of $68.31 \%$ and $84.46 \%$ were reached for classification into four classes using SVM MWV and classification into three classes (drowsiness and fatigue are one class) using SVM WTA, respectively. Anusha et al. [76] detect stress using binary classification. Using single modality (EDA) features and k-nearest neighbors $(\mathrm{kNN})$ classifier they achieve cross-validation accuracy of $93.13 \%$. The highest accuracy $(97.13 \%)$ was obtained using EDA and skin temperature features and classifier ensemble: quadratic discriminant analysis (QDA), SVM, kNN. Chen et al. [142] used ECG, hand and foot EDA and respiratory signal for stress monitoring and EEG and EOG for vigilance monitoring. Features generated from wavelet decomposition, further evaluated by filter-based feature selection are an input into transfer learning classifier. The reported averaged detection accuracy was $89.59 \%$. Recently, de Naurois et al. [143] described the drowsiness detection and prediction model with neural network classifier and different physiological and behavioral parameters (HR, HRV, respiration rate etc.) and vehicle data (SWM, speed etc.).

Surprisingly, not many research papers describe application of deep learning approaches for stress or fatigue detection of drivers. An EEG-based fatigue detection has been described in [144]. CNN was used together with residual learning. Authors showed better predictive power (with accuracy slightly over $84 \%$ ) of their approach in comparison to traditional approaches (features + classification). A camera based approach using pretrained deep neural network (AlexNet, VGG16) has been tested in [145] for driver's emotion recognition, which influences the driving behavior. The emotion recognition accuracy varied from $97.4 \%$ to $98.8 \%$, for different datasets. A Deep Convolutional Autoencoding Memory Network was used for mental fatigue detection in general settings (with possible application to drivers) using ECG and EDA signals with accuracy of $82.9 \%$ [146].

\section{EXPERIMENT SCENARIOS}

\section{A. Simulators vs. real conditions}

Car simulators are used in many studies due to many advantages - a possibility to control the experimental conditions (lighting, temperature, audio noise) [26], [58], low level of signal interference [79], safety [22], drive scenario choice and setting (traffic density, probability of accidents, sounds, number of lanes, day time, curves, environment) [22], [77]. On the other hand, the drivers in a simulator do not feel the same level of stress as drivers in real conditions, because they feel safe and do not necessarily try hard to keep awake [79], [17]. The fatigue can be equally studied in both simulator-based and real word conditions as shown by Philip et al. [165]. However, the stress studies might be influenced when using driving simulator due to limited physical and perceptual fidelity. Thus, the 
conclusions from these studies must be carefully interpreted.

Simulator can be designed as a full car cabin as used in [58] with steering wheel, dashboard, pedals, controls and automatic signal transmission. Virtual scenario is projected in front of the driver and car behavior is monitored by the computer.

In some studies, such as [22], low-cost version of the simulator is used. It consists of laptop with installed simulation software.

Another way to assemble relatively low-cost driving simulator is to use an immersive virtual reality (VR) system [147]. Immersive VR utilizes a head-mounted display (HMD) with stereoscopic projection. It also allows the user to freely move the head to look around. Some VR headsets can also be equipped with eye-tracking devices [148]. The two main downsides of VR driving simulators are increased risk of motion — or more precisely "simulator" - sickness [147], [149] and potential incompatibilities of VR setup with physiological recordings (for instance, EEG cap cannot be used with most headsets, because of the straps holding the HMD in place).

Tests in real conditions (on-the-road) can be conducted in the city as described in [27]. In this case there was no special scenario - the drivers just drove one route for 10 working days with overall $300 \mathrm{~km}$ distance travelled. The values of the LF/HF feature were then figured in the map (using GPS) to investigate the relationship between them [27]. The driver can be alone in the car or with other person such as driving instructor [9]. Study [26] was conducted in a city in real traffic - the driving environment was a busy road including interchanges, two tunnels and lots of traffic lights, but there was also no special scenario.

\section{B. Fatigue and Stress Induction}

According to Matthews et al. [150], it is possible to artificially induce fatigue by prolonged simulator drive, but other factors should also be taken into account, especially workload factors. Authors discussed that there are two types of experimental fatigue induction - active and passive. Active is defined by increased demands, while passive is based on monotony and boredom. Later studies showed differences in effects these two types of fatigue induce. For example, studies from Saxby et al. [151], [152] showed that there is significant reduction in alertness and reaction times and increase in crash probability in passively fatigued drivers. Similar results were found by Gastaldi et al. [69], who further pointed out the importance of circadian factors. Different way to induce fatigue is to expose the subjects to sleep deprivation. Study [153] showed that sleep deprivation, among others, leads to higher number of inappropriate line crossings and notably influences reaction times. Another study [58] compared individuals after normal sleep and 24-hour sleep deprivation. Moreover, the virtual road scenario was monotonous with low-volume sound to enhance drowsiness of the driver. Sleep deprivation was used in [77] as well. Person after at least 7 hours of sleep was considered as not sleep-deprived, 4 and less hour sleep means partial sleep deprivation and more than 20 hours without sleep induced full sleep deprivation [77]. In [22], the simulation drive was set to two hours of drive on monotonous road without other vehicles bolstered by monotonous sounds.

The stressors can influence the driver differently [79]. While for one driver, e.g. the darkness means no stress, it causes highlevel stress in another; there exist individual differences. Therefore, different stressors have been used in current studies. Busy city roads are by themselves stressful for many drivers and were exploited in [26]. Environmental conditions such as night driving, driving in a cold $\left(13^{\circ} \mathrm{C}\right)$ and hot $\left(40^{\circ} \mathrm{C}\right)$ environments were applied in [79] as physical stress stimuli. As mental stressors, noisy environment (loud music), dark alleys, and solving some mathematical problems were used [79]. In study [88] the drivers are stressed by unexpected sound effects and car crash sound accompanied by black screen instead of drive simulation. Crowded roads and vehicle horns also belong to stressors [22].

\section{Acquisition Systems for Drivers Monitoring}

The acquisition systems for complex data monitoring can be assembled from single units used for driving data acquisition, physiological signals acquisition and video-sequences recording. Below, few examples are described, representing different approaches to data acquisition.

A commercially available systems and their combination are used in many studies. For example, versatile Biopac MP100 (Biopac Systems Inc, Goleta, USA) system was used in [57] for ECG (sampling rate $\mathrm{fs}=200 \mathrm{~Hz}$ ) and EDA (fs $=50 \mathrm{~Hz}$ ) signal recording with 12-bit resolution. For 2-leads ECG recording, Bitmed eXim Pro device with sampling frequency of $256 \mathrm{~Hz}$ was used in [77]. For the respiration tracking, the image-based Kinect system was used in [58] together with two $1 \mathrm{Mpx}$ fisheye infrared cameras Texas Instruments PAC16 PoC and MAXIM MAX9271 FRCAM. This study proved high correlation (more than 0.98) between Kinect and plethysmography belt in laboratory conditions. It was also shown that the front position of the camera provides better results than lateral position. Haouij et al. [40] used Empatica E4 wristband for EDA, PPG, skin temperature and motion measurement and chest belt Zephyr Bioharness for ECG, respiration rate, and skin temperature sensing. They used Intel Edison development kit to measure environmental data temperature, humidity, pressure, luminance, sound. Finally, two GoPro cameras monitored inner and outer car environment and GPS sensor integrated in the smartphone was used for position recording.

The integrated sensors, usually developed by the research groups, are also used. They can be integrated into modern garment such as T-Shirt with ECG and breathing sensors [27], or directly into steering wheel as described in [9], [26], for the case of ECG sensors. The advantage of these integrations is no need of on-body electrodes, thus it is more comfortable for the user [26]. On the other hand, the disadvantage lays in necessity of holding the steering wheel usually by both hands or in a particular manner, otherwise the accuracy of HRV analysis decreases [26], [79]. Nevertheless, the high correlation (> 0.96) between the steering wheel integrated sensors and the chest- 
leads system using Biopac MP150 with sampling frequency of $200 \mathrm{~Hz}$ has been shown in [26]. A 9-DOF IMU, which includes ACC, gyroscope and magnetometer, was integrated into glove together with PPG sensor [82]. Choi et al. [22] designed an experimental wearable wrist tracker which records PPG, EDA, temperature, acceleration, and rate of rotation using integrated gyroscope. The device is comfortable without the necessity of electrodes adhering and it does not influence the behavior of the driver. Another experimental device, including optical sensor for PPG recording and 3-axis ACC was used in [80]. This device was placed on the earlobe and worked with sampling rate of $100 \mathrm{~Hz}$.

More complex solution is described in [79] - the "U-car" project. The ECG, PPG, EDA sensors are integrated in steering wheel while another ECG and respiration belt in a seat. Among others, ECG was recorded also using electrodes in both steering wheel and seat. This study also uses reference device Biopac MP150; the results from both devices highly correlate (>0.96) [79]. Commercially available complex solutions are also available. For example, Vehicle Testing Kit (Ergoneers $\mathrm{GmbH}$.) measures and analyzes synchronously behavioral data (Eye-Tracking, Video, Audio), driver performance data (CAN interface, Mobileye ${ }^{\circledR}$, GPS) and experimental leader inputs (triggers, notes).

\section{Annotations}

The annotation of level of stress or fatigue differs in different studies in both, the number of levels and a way of stress/fatigue evaluation. Typically, the evaluation is subjective, provided by observer siting in the car or using a questionnaire. The combination of these approaches is also used. But in some papers the scale is not clearly defined. Here we describe few papers to show different evaluation approaches of stress and fatigue.

In [57] stress is classified into four groups: 0 - no stress, 1 low stress, 2 - medium stress, 3 - high stress. For the final annotations, the video and self-annotation of the driver were used [57]. A 9-level scale subjective rating of stress according to Kakizaki et al. [138] was used to evaluate stress in [139] and [140]. This 9-level is based on self-evaluation of stress by selecting a number between 1 (not stressful at all) and 9 (extremely stressful) in a questionnaire every 10 minutes. Selfevaluation of stress was used in [79]; it was done right after each stress condition and was revised after driving. Value 0 was for the lowest stress and 10 for the highest stress. Similarly, self-evaluation of stress into five levels ( 1 pleasant, 2 normal, 3 low stress, 4 medium stress, 5 high stress) each 5 minutes was applied in [22]. In [84], the study participants judged their mental and physical fatigue every 10 minutes without interruption of drive using questionnaire. For the mental fatigue they have prepared words uncomfortable/comfortable, distracted/concentrated, anxious/quiet and for physical fatigue there were stiff/flexible body, sleepy/energetic, bleary/clear. The subject should evaluate these states into 7 levels. The level of drowsiness was assessed into one of 5 groups ( 1 not drowsy, 2 slightly drowsy, 3 moderately drowsy, 4 very drowsy, 5 extremely drowsy) using on-board camera [22]. The assessment was provided visually on the basis of facial expression, eye blinking frequency, yawning, mean percent eye closure increase. Vicente et al. [77] annotated driver's state by external observes in real time each minute into 3 levels - awake, fatigued, and drowsy. External observers take into consideration body and face movements and the final decision was based on majority ballot [172].

\section{E. Driving Tasks}

A number of approaches have been used to analyze driver behavior. Driving operations are chosen with respect to the objectives of the study. Driving tasks are mostly dependent on whether the behavior of drivers is analyzed in real-time traffic, on a test track with the exclusion of other vehicles or on a driving simulator. Another factor influencing applied driving tasks is also the technology used for the data collection whether it is physiological measures, behavioral measures, vehicle data analysis or the combination of selected parameters.

In order to analyze fatigue, mostly driving simulator scenarios have been used, although many authors point to distortions of obtained data. The driving experience on the simulator is the most commonly used monotonous environment. However, the simulation environment also allows for changing the weather for the purpose of behavior analysis, for example the assignment of a strong side wind that forces driver to regulate vehicle movement to stay in the lane [66], [118], [153]. During the monotonous sections, it is not possible to analyze some parameters such as muscle fatigue, reaction time, speeding, compensatory behavior. Also, a combination of monotonous environments with other scenarios has been used, e.g. with objects to interrupt monotony. Some approaches also use the assignment of objects to which the driver must respond. One of the most commonly used techniques is driving behind the leading vehicle. The fatigue induction procedure while following a lead vehicle was used e.g. in [154], [155]. Thiffault and Bergeron [66] used 3 driving scenarios - in the first scenery the roadside contained only grass, the second scenery contained also pairs of pine trees, the third scenery was intended to be monotonous but without repetitive environment including houses, farms and pedestrians on the roadside. Matthews and Desmond [155] used pedestrian detection task, during which participants were asked to detect movements in scene.

\section{Methods used In Mass-Produced Cars}

The driver fatigue detection systems are increasingly built in mass-produced cars. Most of the fatigue detection systems create a driver profile and detect fatigue due to changes in driving pattern. The most commonly used fatigue detection parameter is monitoring the driving along white lines marking the lane in which car is [156], [157], [158], [159]. When a car runs irregularly between the white lines, it means the driver is tired. Another parameter for fatigue detection is also the reaction time at which the drivers realize that they are close to the white line [156], [157]. Another parameter describes how much the driver responds to being close to the white line [158]. 
If the driver is tired, steering wheel rotation will be greater than necessary. The above-mentioned parameters are used by Mercedes, Volvo and Ford. Volkswagen has developed a parameter based on the fact that the relaxed driver still moves a steering wheel a little. A tired driver stops these little moves [160]. Another approach to detecting fatigue is to monitor the driver with the camera [161]. The used parameters for fatigue detection are blinking frequency, head orientation, position of the driver's upper and lower eyelids and slackened facial muscles. These features are not as widely available; they are used by Cadillac, Toyota and Lexus.

The mass-produced cars usually signal the fatigue by an audible or visual alert or as vibrating the steering wheel. There exist active mechanisms that help the drivers to eliminate their faults and also warn them of danger. If the drivers already fall asleep for a while and cross the alert strips, they warn them [17]. Some cars do little movements of steering wheel to make the drivers driving in their lane (lane assistant).

\section{DISCUSSION}

Majority of published papers describe driving sessions simulated in laboratory environment. The advantage of this approach is safety, cheapness, reproducibility, much more possibilities for testing different sensing scenarios from placing of electrodes to type of road and environment. On the other hand, it cannot fully replace real driving. Behavior of the drivers is different if they know that it is only simulation and they cannot be injured or cause any accident. In case of real driving, ethical issues arise. Is it acceptable to drive in normal traffic knowingly fatigued? If the drive scenario is planned in a real traffic, but in more quiet streets and roads, then the results will be probably a little bit distorted or uncomplete.

Stress and fatigue are related as described in Introduction. Sometimes it is difficult or impossible to distinguish between them. But both influence negatively the driver performance and their influence can be different, which makes the analysis more complicated. Therefore, the trend in stress and fatigue detection is the data fusion and application of advanced machine learning methods. Different types of data such as biosignals, car signals and videos of driver and car behavior are fused. Data fusion and machine learning methods enable to detect stress and fatigue more robustly and accurately. In practice, not all sensors for data fusion are acceptable, especially the contact ones. It is probably one of the reasons why this approach is still not plentifully used in mass-produced cars.

Even if the fatigue and stress detection systems would be perfect, they cannot compel the driver to stop. It is always the driver's decision. In Salmon's survey [8] which included 316 participants, $66.5 \%$ of them drove fatigued. The reasons why they drove in this risky state were different: time pressure, work requirements, shift work, long journeys, and expectations of other people. Furthermore, $18 \%$ of people did not realize they are fatigued.

In a spite of high effort of car manufacturer to develop and introduce autonomous vehicles, it is now obvious that the way to fully autonomous solution will be longer than predicted few years ago. There are many obstacles, including social acceptance, legal issues of liability, human-vehicle interaction and increased cost of car (due to advanced software, hardware and sensors, e.g. LIDAR). These hot topics are being discussed in order to find solutions for these problems $[166,167]$. Furthermore, $3^{\text {rd }}$ level of autonomous vehicle (classification according to National Highway Traffic Safety Administration [168]) will still need a driver, ready to intervene and driver's fatigue (or even sleep) needs to be monitored. The $4^{\text {th }}$ level of autonomous driving will also need some systems for drivers monitoring in order to monitor possible stress.

\section{CONCLUSION}

High effort of research groups and car manufacturers can be observed in the field of drivers' health conditions monitoring during last decade. As the drivers' behavior is complex process, the robust and precise monitoring with real impact on the road safety is still a challenging task.

The acquisition system must not affect the drivers - the noncontact acquisition method must be used as well as sensors integrated directly into cockpit. Small number of contact sensors can be probably acceptable, e.g. placed on the wrist, chest or in the form of glasses. However, the signal quality and availability is difficult to maintain during whole driving time.

Nevertheless, current development of methods in machine learning seems to provide new possibilities of data analysis and classification. Particularly, deep learning approaches, which became a standard and state-of-the-art approach in many classification tasks, are promising also in this area.

The lack of complex datasets from real driving conditions and difficulties connected with the inter-drivers' variability are probably the main obstacles, which limit the better understanding to drivers' physiological processes during driving. Such datasets would allow experimental fusion of specific biosignals and car features and design of robust detection systems for drivers' stress, drowsiness and fatigue.

\section{REFERENCES}

[1] European Road Safety Observatory, "Annual Accident Report 2018," 2019. [Online]. Available: https://ec.europa.eu/transport/road_safety/ sites/roadsafety/files/pdf/statistics/dacota/asr2018.pdf

[2] European Commission, "European Commission presents final road safety figures for 2017 on World Day of Remembrance for Road Traffic Victims," Nov. 11, 2018. [Online]. Aailable: https://ec.europa.eu/transport/media/news/2018-11-16-road-safetyfigures-2017_en

[3] World Health Organization, "Global status report on road safety 2018," 2018. [Online]. Available: https://www.who.int/ violence_injury_prevention/road_safety_status/2018/en/

[4] World Health Organization, "Road traffic injuries," 2018. [online]. Available: https://www.who.int/en/news-room/fact-sheets/detail/roadtraffic-injuries

[5] World Health Organization, "Global Health Observatory (GHO) data," 2013. [Online]. https://www.who.int/gho/road_safety/en/

[6] Organisation for Economic Co-operation and Development, "Road Safety Annual Report 2017,” 2017. [Online]. Available: https://www.oecd-ilibrary.org/transport/road-safety-annual-report2017_irtad-2017-en

[7] European Commission, "Road Safety: Data show improvements in 2017 but renewed efforts are needed for further substantial progress," Apr. 10, 2018. [online]. Available: https://ec.europa.eu/transport/news/2018-0410-road-safety-data-show-improvements_en 
[8] P. M. Salmon, G. J. M. Read, V. Beanland, J. Thompson, A. J. Filtness, A. Hulme, R. McClure, and I. Johnston, "Bad behaviour or societal failure? Perceptions of the factors contributing to drivers' engagement in the fatal five driving behaviours," Appl. Ergon., vol. 74, pp. 162-171, Jan. 2019, DOI: 10.1016/j.apergo.2018.08.008.

[9] S. Begum, "Intelligent Driver Monitoring Systems Based on Physiological Sensor Signals: A Review," in Proc. 16th Int. IEEE Conf. Intell. Transp. Syst. (ITSC), Hague, Netherlands, Oct. 2013, pp. 282289.

[10] J. Davidović, D. Pešić, and B. Antić, "Professional drivers' fatigue as a problem of the modern era," Transp. Res. Pt. F-Traffic Psychol. Behav., vol. 55, pp. 199-209, May 2018, DOI: 10.1016/j.trf.2018.03.010.

[11] G. Sikander and S. Anwar, "Driver Fatigue Detection Systems: A Review," IEEE Trans. Intell. Transp. Syst., vol. 20, no. 6, pp. 23392352, Oct. 2018, DOI: 10.1109/TITS.2018.2868499.

[12] P. Thiffault and J. Bergeron, "Fatigue and individual differences in monotonous simulated driving," Pers. Individ. Differ., vol. 34, no. 1, pp. 159-176, Jan. 2003, DOI: 10.1016/s0191-8869(02)00119-8.

[13] G. Matthews, P. A. Desmond, L. Joyner, B. Carcary, and K. Gilliland, "A comprehensive questionnaire measure of driver stress and affect," in Proc. Int. Conf. Traffic Transp. Psychol. (ICTTP), 1997, pp. 317-324.

[14] P. A. Desmond and G. Matthews, "Individual differences in stress and fatigue in two field studies of driving," Transp. Res. Pt. F-Traffic Psychol. Behav., vol. 12, no. 4, pp. 265-276, Jul. 2009, DOI: 10.1016/j.trf.2008.12.006.

[15] S. K. L. Lal and A. Craig, "Driver fatigue: Electroencephalography and psychological assessment,", Psychophysiology, vol. 39, no. 3, pp. 313321, May 2002, DOI: 10.1017/s0048577201393095.

[16] G. Matthews and P. A. Desmond, "Personality and multiple dimensions of task-induced fatigue: a study of simulated driving," Pers. Individ. Differ., vol. 25, no. 3, pp. 443-458, Sep. 1998, DOI: 10.1016/s01918869(98)00045-2.

[17] A. Chowdhury, R. Shankaran, M. Kavakli, and M. M. Haque, "Sensor Applications and Physiological Features in Drivers' Drowsiness Detection: A Review," IEEE Sens. J., vol. 18, no. 8, pp. 3055-3067, Apr. 2018, DOI: 10.1109/jsen.2018.2807245.

[18] Transport Accident Comission, "Avoiding driver fatigue." [online]. Available: http://www.tac.vic.gov.au/road-safety/safe-driving/tips-andtools/fighting-fatigue

[19] H. Wang, "Application Heart Rate Variability to Driver Fatigue Detection of Dangerous Chemicals Vehicles," in Proc. 2014 5th Int. Conf. Intell. Syst. Des. Eng. Applicat. (ISDEA), Hunan, China, Jun. 2014, pp. 218-221.

[20] J. Rogé, T. Pebayle, and A. Muzet, "Variations of the level of vigilance and of behavioural activities during simulated automobile driving," Accid. Anal. Prev., vol. 33, no. 2, pp. 181-186, Mar. 2001, DOI: 10.1016/s0001-4575(00)00029-4.

[21] N. Munla, M. Khalil, A. Shahin, and A. Mourad, "Driver Stress Level Detection Using HRV Analysis," in Proc. 2015 Int. Conf. Adv. Biomed. Eng. (ICABME), Beirut, Lebanon, Sept. 2015, pp. 61-64.

[22] M. Choi, G. Koo, M. Seo, and S. W. Kim, "Wearable Device-Based System to Monitor a Driver's Stress, Fatigue, and Drowsiness," IEEE Trans. Instrum. Meas., vol. 67, no. 3, pp. 634-645, Mar. 2018, DOI: 10.1109/tim.2017.2779329.

[23] Y. Choi, Q. Zhang, and S. Ko, "Noninvasive cuffless blood pressure estimation using pulse transit time and Hilbert-Huang transform," Comput. Electr. Eng., vol. 39, no. 1, pp. 103-111, Jan. 2013, DOI: 10.1016/j.compeleceng.2012.09.005.

[24] P. Sterling and J. Eyer, "Allostasis: A new paradigm to explain arousal pathology," in Handbook of Life Stress, Cognition and Health. John Wiley \& Sons, 1988, pp. 629-649.

[25] J. Schulkin, "Allostasis: a neural behavioral perspective," Hormon. Behav., vol. 43, no. 1, pp. 21-27, Jan. 2003, DOI: 10.1016/s0018506x(02)00035-1.

[26] H. B. Lee, J. M. Choi, J. S. Kim, Y. S. Kim, H. J. Back, M. S. Ryu, R. H. Sohn, and K. S. Park, "Nonintrusive biosignal measurement system in a vehicle," in Conf. Proc. IEEE Eng. Med. Biol. Soc., Lyon, France, Aug. 2007, pp. 2303-2306.

[27] S. De Nadai, M. D'Incà, F. Parodi, M. Benza, A. Trotta, E. Zero, L. Zero, and R. Sacile, "Enhancing safety of transport by road by on-line monitoring of driver emotions," in Proc. 2016 11th System of Systems Eng. Conf. (SoSE), Kongsberg, Norway, Jun. 2016.

[28] T. H. Holmes and R. H. Rahe, "The social readjustment rating scale," $J$. Psychosomat. Res., vol. 11, no. 2, pp. 213-218, 1967, DOI: 10.1016/0022-3999(67)90010-4.
[29] E. Gulian, G. Matthews, A. I. Glendon, D. R. Davies, and L. M. Debney, "Dimensions of driver stress," Ergonomics, vol. 32, no. 6, pp. 585-602, Jun 1989, DOI: 10.1080/00140138908966134.

[30] G. Matthews, L. Dorn, and A. I. Glendon, "Personality correlates of driver stress," Pers. Individ. Differ., vol. 12, no. 6, pp. 535-549, 1991, DOI: 10.1016/0191-8869(91)90248-a.

[31] B. S. McEwen and E. Stellar, "Stress and the individual. Mechanisms leading to diseas," Arch. Intern. Med., vol. 153, no. 18, pp. 2093-2101, Sep. 1993, DOI: 10.1001/archinte.153.18.2093.

[32] R. L. Repetti, T. F. Robles, and B. Reynolds, "Allostatic processes in the family," Dev. Psychopathol., vol. 23, no. 3, pp. 921-938, Aug. 2011, DOI: $10.1017 / \mathrm{s} 095457941100040 x$.

[33] B. S. McEwen and E. Lasley, The End of Stress As We Know It. Washington, DC, US: Joseph Henry Press, 2002.

[34] G. Kempermann, H. G. Kuhn, and F. H. Gage, "Experience-induced neurogenesis in the senescent dentate gyrus," J. Neurosci., vol. 18, no. 9, pp. 3206-3212, May 1998.

[35] S. J. Colcombe, A. F. Kramer, K. I. Erickson, P. Scalf, E. McAuley, N. J. Cohen, A. Webb, G. J. Jerome, D. X. Marquez, and S. Elavsky, "Cardiovascular fitness, cortical plasticity, and aging," Proc. Natl. Acad. Sci. U. S. A., vol. 101, no. 9, pp. 3316-3321, Mar. 2004, DOI: 10.1073/pnas.0400266101.

[36] R. M. Sapolsky, L. M. Romero, and A. U. Munck, "How Do Glucocorticoids Influence Stress Responses? Integrating Permissive, Suppressive, Stimulatory, and Preparative Actions," Endocr. Rev., vol. 21, no. 1, pp. 55-89, 2000, DOI: 10.1210/edrv.21.1.0389.

[37] A. Sahayadhas, K. Sundaraj, and M. Murugappan, "Detecting Driver Drowsiness Based on Sensors: A Review," Sensors, vol. 12, no. 12, pp. 16937-16953, Dec. 2012, DOI: 10.3390/s121216937.

[38] J. A. Healey and R. W. Picard, "Detecting stress during real-world driving tasks using physiological sensors," IEEE Trans. Intell. Transp. Syst., vol. 6, no. 2, pp. 156-166, Jun. 2005, DOI: $10.1109 /$ tits.2005.848368.

[39] A. L. Goldberger, L. A. Amaral, L. Glass, J. M. Hausdorff, P. C. Ivanov, R. G. Mark, J. E. Mietus, G. B. Moody, C. K. Peng, and H. E. Stanley, "PhysioBank, PhysioToolkit, and PhysioNet - Components of a new research resource for complex physiologic signals," Circulation, vol. 101, no. 23, pp. E215-E220, Jun. 2000, DOI: 10.1161/01.cir.101.23.e215.

[40] N. E. Haouij, J. M. Poggi, S. Sevestre-Ghalila, R. Ghozi, and M. Jaidane, "Affective ROAD System and Database to Assess Driver's Attention," Proc. 33rd Annu. ACM Symp. Appl. Comput. (SAC), Pau, France, Apr. 2018, pp. 800-803.

[41] S. Schneegass, B. Pfleging, N. Broy, A. Schmidt, and F. Heinrich, "A data set of real world driving to assess driver workload," in Proc. 5th Int. Conf. Automot. User Interfaces and Interact. Veh. Applicat. (AutomotiveUI), Eindhoven, Netherlands, Oct. 2013, pp. 150-157.

[42] P. Taylor, N. Griffiths, A. Bhalerao, D. Watson, X. Zhou, and T. J. Popham, "Warwick-JLR Driver Monitoring Dataset (DMD): A public Dataset for Driver Monitoring Research," in Cognitive Load and InVehicle Human-Machine Interaction (CLW), Eindhoven, Netherlands, Oct. 2013.

[43] P. Taylor, N. Griffiths, A. Bhalerao, Z. Xu, A. Gelencser, and T. J. Popham, "Warwick-JLR driver monitoring dataset (DMD) : statistics and early findings," in Proc. 7th Int. Conf. Automot. User Interfaces and Interact. Veh. Applicat. (AutomotiveUI), Nottingham, United Kingdom, Sep. 2015.

[44] P. Taylor, "Data Mining of Vehicle Telemetry Data," Ph.D. Dissertation, Dept. Comput. Sci., Warwick Univ., Warwick, United Kingdom, 2015.

[45] J. Birjandtalab, D. Cogan, M. B. Pouyan, and M. Nourani, "A non-EEG Biosignals Dataset for Assessment and Visualization of Neurological Status," in 2016 IEEE Int. Workshop Signal Process. Syst. (SiPS), Dallas, TX, USA, Oct. 2016, pp. 110-114.

[46] R. Subramanian, J. Wache, M. K. Abadi, R. L. Vieriu, S. Winkler, and N. Sebe, "ASCERTAIN: Emotion and Personality Recognition Using Commercial Sensors," IEEE Trans. Affect. Comput., vol. 9, no. 2, pp. 147-160, Apr.-Jun. 2018, DOI: 10.1109/taffc.2016.2625250.

[47] S. Koelstra, C. Mühl, M. Soleymani, J.-S. Lee, A. Yazdani, T. Ebrahimi, T. Pun, A. Nijholt, and I. Patras, "DEAP: A Database for Emotion Analysis Using Physiological Signals," IEEE Trans. Affect. Comput., vol. 3, no. 1, pp. 18-31, Jan.-Mar. 2012, DOI: 10.1109/t-affc.2011.15.

[48] M. Soleymani, J. Lichtenauer, T. Pun, and M. Pantic, "A Multimodal Database for Affect Recognition and Implicit Tagging," IEEE Trans. 
Affect. Comput., vol. 3, no. 1, pp. 42-55, Jan.-Mar. 2012, DOI: $10.1109 /$ t-affc. 2011.25

[49] M. K. Abadi, R. Subramanian, S. M. Kia, P. Avesani, I. Patras, and N. Sebe, "DECAF: MEG-Based Multimodal Database for Decoding Affective Physiological Responses," IEEE Trans. Affect. Comput., vol. 6, no. 3, pp. 209-222, Jul.-Sep. 2015, DOI: 10.1109/taffc.2015.2392932.

[50] T. Ganchev, V. Markova, I. Lefterov, and Y. Kalinin, "Overall design of the SLADE data acquisition system," in Proc. 2nd Int Sci. Conf. Intell. Inform. Technol. Ind. (IITI), 2018, pp. 56-65.

[51] J. A. Miranda-Correa, M. K. Abadi, N. Sebe, and I. Patras, "AMIGOS: A Dataset for Affect, Personality and Mood Research on Individuals and Groups," IEEE Trans. Affect. Comput., 2018, DOI: 10.1109/TAFFC.2018.2884461.

[52] D. S. Wickramasuriya, C. Qi, and R. T. Faghih, "A State-Space Approach for Detecting Stress from Electrodermal Activity," in Conf. Proc. IEEE Eng. Med. Biol. Soc. (EMBS), Honolulu, HI, USA, Jul. 2018, pp. 3562-3567.

[53] A. Jafari, A. Ganesan, C. S. K. Thalisetty, V. Sivasubramanian, T. Oates, and T. Mohsenin, "SensorNet: A Scalable and Low-Power Deep Convolutional Neural Network for Multimodal Data Classification," IEEE Trans. Circuits Syst. I-Regul. Pap., vol. 66, no. 1, pp. 274-287, Jan. 2019, DOI: 10.1109/tcsi.2018.2848647.

[54] A. Jafari, M. Hosseini, H. Homayoun, and T. Mohsenin, "A Scalable and Low Power DCNN for Multimodal Data Classification," in Proc. Int. Conf. Reconfigurable Comput. FPGAs (ReConFig), Cancun, Mexico, Dec. 2018.

[55] V. Markova and T. Ganchev, "Three-step Attribute Selection for Stress Detection based on Physiological Signals," in Proc. 27th Int. Sci. Conf. Electron. (ET 2018), Sozopol, Bulgaria, Sept. 2018.

[56] V. Markova and T. Ganchev, "Automated Recognition of Affect and Stress evoked by Audio-Visual stimuli," in Proc. 2018 7th Balkan Conf. Lighting (BalkanLight), Varna, Bulgaria, Sept. 2018.

[57] G. Rigas, C. D. Katsis, P. Bougia, and D. I. Fotiadis, "A ReasoningBased Framework for Car Driver's Stress Prediction," in Proc. 16th Mediterranean Conf. Control Automat., Ajaccio, France, Jun. 2008, pp. 627-632.

[58] J. Solaz, J. Laparra-Hernández, D. Bande, N. Rodríguez, S. Veleff, J. Gerpe, and E. Medina, "Drowsiness detection based on the analysis of breathing rate obtained from real-time image recognition," in Transp. Res. Procedia, vol. 14, pp. 3867-3876, 2016, DOI: 10.1016/j.trpro.2016.05.472.

[59] P. H. Ting, J. R. Hwang, J. L. Doong, and M. C. Jeng, "Driver fatigue and highway driving: A simulator study," Physiol. Behav., vol. 94, no. 3, pp. 448-453, Jun. 2008, DOI: 10.1016/j.physbeh.2008.02.015.

[60] S. H. Fairclough and R. Graham, "Impairment of driving performance caused by sleep deprivation or alcohol: A comparative study," Hum. Factors, vol. 41, no. 1, pp. 118-128, Mar. 1999, DOI: $10.1518 / 001872099779577336$.

[61] R. Feng, G. Zhang, and B. Cheng, "An On-Board System for Detecting Driver Drowsiness Based on Multi-Sensor Data Fusion Using Dempster-Shafer Theory," in Proc. 2009 IEEE Int. Conf. Netw. Sens. Control, Okayama, Japan, Mar. 2009, pp. 887-892.

[62] T. Akerstedt, B. Peters, A. Anund, and G. Kecklund, "Impaired alertness and performance driving home from the night shift: a driving simulator study," J. Sleep Res., vol. 14, no. 1, pp. 17-20, Mar. 2005, DOI: 10.1111/j.1365-2869.2004.00437.x.

[63] T. Oron-Gilad, A. Ronen, and D. Shinar, "Alertness maintaining tasks (AMTs) while driving," Accid. Anal. Prev., vol. 40, no. 3, pp. 851-860, May 2008, DOI: 10.1016/j.aap.2007.09.026.

[64] T. Altmüller, "Driver Monitoring and Drowsiness Detection by Steering Signal Analysis," Ph.D. Dissertation, Dept. Elect. Eng. Inform. Technol., Munich Univ., Munich, Germany, 2007.

[65] R. Rossi, M. Gastaldi, and G. Gecchele, "Analysis of driver task-related fatigue using driving simulator experiments," in Procedia - Soc. Behav. Sci., vol. 20, pp. 666-675, 2011, doi: 10.1016/j.sbspro.2011.08.074.

[66] P. Thiffault and J. Bergeron, "Monotony of road environment and driver fatigue: a simulator study," Accid. Anal. Prev., vol. 35, no. 3, pp. 381391, May 2003, DOI: 10.1016/s0001-4575(02)00014-3.

[67] S. Otmani, T. Pebayle, J. Roge, and A. Muzet, "Effect of driving duration and partial sleep deprivation on subsequent alertness and performance of car drivers," Physiol. Behav., vol. 84, no. 5, pp. 715-724, Apr. 2005, DOI: 10.1016/j.physbeh.2005.02.021.

[68] P. A. Desmond, P. A. Hancock, and J. L. Monette, "Fatigue and automation-induced impairments in simulated driving performance,"
Hum. Perform. User Inform. Highway Des., pp. 8-14, Jan. 1998, DOI: 10.3141/1628-02.

[69] M. Gastaldi, R. Rossi, and G. Gecchele, "Effects of driver task-related fatigue on driving performance," in Procedia - Soc. Behav. Sci., vol. 111, pp. 955-964, Feb. 2014, DOI: 10.1016/j.sbspro.2014.01.130.

[70] H. Zhang, X. Yan, C. Wu, and T. Z. Qiu, "Effect of Circadian Rhythms and Driving Duration on Fatigue Level and Driving Performance of Professional Drivers," Transp. Res. Record, no. 2402, pp. 19-27, Dec. 2014, DOI: 10.3141/2402-03.

[71] R. Simons, M. Martens, J. Ramaekers, A. Krul, I. Klöpping-Ketelaars, and G. Skopp, "Effects of dexamphetamine with and without alcohol on simulated driving," Psychopharmacology, vol. 222, no. 3, pp. 391-399, Aug. 2012, DOI: 10.1007/s00213-011-2549-0.

[72] D. Das, S. Zhou, and J. D. Lee, "Differentiating Alcohol-Induced Driving Behavior Using Steering Wheel Signals," IEEE Trans. Intell. Transp. Syst., vol. 13, no. 3, pp. 1355-1368, Sep. 2012, DOI: $10.1109 /$ tits.2012.2188891.

[73] H. Zhang, C. Wu, Z. Huang, X. Yan, and T. Z. Qiu, "Sensitivity of Lane Position and Steering Angle Measurements to Driver Fatigue," Transp. Res. Record, no. 2585, pp. 67-76, Jan. 2016, DOI: 10.3141/2585-08.

[74] J. Krajewski, D. Sommer, U. Trutschel, D. Edwards, and M. Golz, "Steering Wheel Behavior Based Estimation of Fatigue," in Proc. 5th Int. Driving Symp. Hum. Factors Driver Assess. Train. Veh. Des., Big Sky, MT, USA, Jan. 2009, pp. 118-124.

[75] M. Lohani, B. R. Payne, and D. L. Strayer, "A Review of Psychophysiological Measures to Assess Cognitive States in RealWorld Driving," Front. Hum. Neurosci., vol. 13, pp. 1-27, Mar. 2019, DOI: 10.3389/fnhum.2019.00057.

[76] A. S. Anusha, J. Jose, S. P. Preejith, J. Jayaraj, and S. Mohanasankar, "Physiological signal based work stress detection using unobtrusive sensors," Biomed. Phys. Eng. Express, vol. 4, no. 6, pp. 1-26, Nov. 2018, DOI: 10.1088/2057-1976/aadbd4.

[77] J. Vicente, P. Laguna, A. Bartra, and R. Bailón, "Drowsiness detection using heart rate variability," Med. Biol. Eng. Comput., vol. 54, no. 6, pp. 927-937, Jun. 2016, DOI: 10.1007/s11517-015-1448-7.

[78] R. Bailón, G. Laouini, C. Grao, M. Orini, P. Laguna, and O. Meste, "The Integral Pulse Frequency Modulation Model With Time-Varying Threshold: Application to Heart Rate Variability Analysis During Exercise Stress Testing," IEEE Trans. Biomed. Eng., vol. 58, no. 3, pp. 642-652, Mar. 2011, DOI: 10.1109/tbme.2010.2095011.

[79] H. J. Baek, H. B. Lee, J. S. Kim, J. M. Choi, K. K. Kim, and K. S. Park, "Nonintrusive Biological Signal Monitoring in a Car to Evaluate a Driver's Stress and Health State," Telemed. J. e-Health, vol. 15, no. 2, pp. 182-189, Mar. 2009, DOI: 10.1089/tmj.2008.0090.

[80] Y. H. Lin, C.-F. Lin, and H.-Z. You, "A Driver's Physiological Monitoring System Based on a Wearable PPG Sensor and a Smartphone," in Commun. Comput. Inform. Sci., vol. 223, pp. 326-335, Sept. 2011.

[81] R. R. Singh, S. Conjeti, and R. Banerjee, "A comparative evaluation of neural network classifiers for stress level analysis of automotive drivers using physiological signals," Biomed. Signal Process. Control, vol. 8, no. 6, pp. 740-754, Nov. 2013, DOI: 10.1016/j.bspc.2013.06.014.

[82] D. S. Lee, T. W. Chong, and B. G. Lee, "Stress Events Detection of Driver by Wearable Glove System," Ieee Sens. J., vol. 17, no. 1, pp. 194204, Jan. 2017, DOI: 10.1109/jsen.2016.2625323.

[83] X. Wang, B. Liu, L. Xie, X. Yu, M. Li, and J. Zhang, "Cerebral and neural regulation of cardiovascular activity during mental stress," Biomed. Eng. Online, vol. 15, 2016, DOI: 10.1186/s12938-016-0255-1.

[84] Y. Jiang, S. Guo, and S. Deng, "Denoising and Chaotic Feature Extraction of Electrocardial Signals for Driver Fatigue Detection by Kolmogorov Entropy," J. Dyn. Syst. Meas. Control-Trans. ASME, vol. 141, no. 2, pp. 1-7, Feb. 2019, DOI: 10.1115/1.4041355.

[85] N. Keshan, P. V. Parimi, and I. Bichindaritz, "Machine Learning for Stress Detection from ECG Signals in Automobile Drivers," in Proc. 2015 IEEE Int. Conf. Big Data (Big Data), Santa Clara, CA, USA, Oct.Nov- 2015, pp. 2661-2669.

[86] R. W. Picard, E. Vyzas, and J. Healey, "Toward machine emotional intelligence: Analysis of affective physiological state," IEEE Trans. Pattern Anal. Mach. Intell., vol. 23, no. 10, pp. 1175-1191, Oct. 2001, DOI: $10.1109 / 34.954607$.

[87] J. Milagro, E. Gil, J. M. Garzón-Rey, J. Aguiló, R. Bailón, "Inspiration and Expiration Dynamics in Acute Emotional Stress Assessment," in Proc. 2017 Computing in Cardiology (CinC), Rennes, France, Sept. 2017, pp. 1-4, 2017. 
[88] A. Affanni, R. Bernardini, A. Piras, R. Rinaldo, and P. Zontone, "Driver's stress detection using Skin Potential Response signals," Measurement, vol. 122, pp. 264-274, Jul. 2018, DOI: 10.1016/j.measurement.2018.03.040.

[89] D. Malathi, J. D. D. Jayaseeli, S. Madhuri, and K. Senthilkumar, "Electrodermal Activity Based Wearable Device for Drowsy Drivers," in J. Phys.: Conf. Ser., Jan. 2018, vol. 1000, DOI: 10.1088/17426596/1000/1/012048.

[90] D. S. Bari, H. Y. Y. Aldosky, C. Tronstad, H. Kalvoy, and O. G. Martinsen, "Electrodermal responses to discrete stimuli measured by skin conductance, skin potential, and skin susceptance," Skin Res. Technol., vol. 24, no. 1, pp. 108-116, Feb. 2018, DOI: 10.1111/srt.12397.

[91] G. Borghini, L. Astolfi, G. Vecchiato, D. Mattia, and F. Babiloni, "Measuring neurophysiological signals in aircraft pilots and car drivers for the assessment of mental workload, fatigue and drowsiness," Neurosci. Biobehav. Rev., vol. 44, pp. 58-75, Jul. 2014, DOI: 10.1016/j.neubiorev.2012.10.003.

[92] M. Simon, E. A. Schmidt, W. E. Kincses, M. Fritzsche, A. Bruns, C. Aufmuth, M. Bogdan, W. Rosenstiel, and M. Schrauf, "EEG alpha spindle measures as indicators of driver fatigue under real traffic conditions," Clin. Neurophysiol., vol. 122, no. 6, pp. 1168-1178, Jun. 2011, DOI: 10.1016/j.clinph.2010.10.044.

[93] W. Li, Q. C. He, X. M. Fan, and Z. M. Fei, "Evaluation of driver fatigue on two channels of EEG data," Neurosci. Lett., vol. 506, no. 2, pp. 235239, Jan. 2012, DOI: 10.1016/j.neulet.2011.11.014.

[94] R. Chai, G. R. Naik, T. N. Nguyen, S. H. Ling, Y. Tran, A. Craig, and H. T. Nguyen, "Driver Fatigue Classification With Independent Component by Entropy Rate Bound Minimization Analysis in an EEGBased System," IEEE J. Biomed. Health Inform., vol. 21, no. 3, pp. 715724, May 2017, DOI: 10.1109/jbhi.2016.2532354.

[95] M. K. Wali, M. Murugappan, and B. Ahmmad, "Wavelet Packet Transform Based Driver Distraction Level Classification Using EEG," Math. Probl. Eng., vol. 2013, pp. 1-10, 2013, Art. no. 297587, DOI: 10.1155/2013/297587.

[96] R. Chai, S. H. Ling, P. P. San, G. R. Naik, T. N. Nguyen, Y. Tran, A. Craig, and H. T. Nguyen, "Improving EEG-Based Driver Fatigue Classification Using Sparse-Deep Belief Networks," Front. Neurosci., vol. 11, pp. 1-14, Mar. 2017, Art. no. 103, DOI: 10.3389/fnins.2017.00103.

[97] M. Haak, S. Bos, S. Panic, and L. J. M. Rothkrantz, "Detecting stress using eye blinks and brain activity from EEG signals," in Proc. 1st Driver Car Interaction and Interface (DCII 2008), 2009.

[98] L. G. Hernández, O. M. Mozos, J. M. Frrández, and J. M. Antelis, "EEGbased Detection of Braking Intention under Different Car Driving Conditions", Front. Neuroinform., vol. 12, Art. no. 29, May 2018, DOI: 10.3389/fninf.2018.00029.

[99] H. S. Kim, Y. Hwang, D. Yoon, W. Choi, and C. H. Park, "Driver Workload Characteristics Analysis Using EEG Data from an Urban Road," IEEE Trans. Intell. Transp. Syst., vol. 15, no. 4, pp. 1844-1849, Aug. 2014, DOI: 10.1109/TITS.2014.2333750.

[100] Z. Halim and M. Rehan, "On identification of driving-induced stress using electroencephalogram signals: A framework based on wearable safety-critical scheme and machine learning," Inf. Fusion, vol. 53, pp. 66-79, Jan. 2020, DOI: 10.1016/j.inffus.2019.06.006.

[101] S. Kim, W. Rhee, D. Choi, Y. J. Jang, and Y. Yoon, "Characterizing Driver Stress Using Physiological and Operational Data from RealWorld Electric Vehicle Driving Experiment," Int. J. Automot. Technol., vol. 19 , no. 5, pp. 895-906, Oct. 2018, DOI: 10.1007/s12239-018-00860 .

[102] V. Engert, A. Merla, J. A. Grant, D. Cardone, A. Tusche, and T. Singer, "Exploring the Use of Thermal Infrared Imaging in Human Stress Research," PLoS One, vol. 9, no. 3, pp. 1-11, Mar. 2014, Art. no. e90782, DOI: 10.1371/journal.pone.0090782.

[103] C. K. L. Or and V. G. Duffy, "Development of a facial skin temperaturebased methodology for non-intrusive mental workload measurement," Occup. Ergon., vol. 7, no. 2, pp. 83-94, 2007.

[104] D. Cardone and A. Merla, "New Frontiers for Applications of Thermal Infrared Imaging Devices: Computational Psychopshysiology in the Neurosciences," Sensors, vol. 17, no. 5, pp. 1-21, May 2017, Art. no. 1042, DOI: 10.3390/s17051042.

[105] R. Nelesen, Y. Dar, K. Thomas, and J. E. Dimsdale, "The relationship between fatigue and cardiac functioning," Arch. Intern. Med., vol. 168, no. 9, pp. 943-949, May 2008, DOI: 10.1001/archinte.168.9.943.
[106] J. L. Newton, A. Sheth, J. Shin, J. Pairman, K. Wilton, J. A. Burt, and D. E. Jones, "Lower Ambulatory Blood Pressure in Chronic Fatigue Syndrome," Psychosom. Med., vol. 71, no. 3, pp. 361-365, Apr. 2009, DOI: 10.1097/PSY.0b013e31819ccd2a.

[107] P. J. Barendregt, M. Visser, E. Smets, J. Tulen, A. H. van den Meiracker, F. Boomsma, and H. Markusse, "Fatigue in primary Sjögren's syndrome," Ann. Rheum. Dis., vol. 57, no. 5, pp. 291-295, May 1998, DOI: 10.1136/ard.57.5.291.

[108] S. Milosevic, "Drivers' fatigue studies," Ergonomics, vol. 40, no. 3, pp. 381-389, Mar. 1997, DOI: 10.1080/001401397188215.

[109] N. Hjortskov, D. Rissén, A. K. Blangsted, N. Fallentin, U. Lundberg, and K. Sogaard, "The effect of mental stress on heart rate variability and blood pressure during computer work," Eur. J. Appl. Physiol., vol. 92, no. 1-2, pp. 84-89, Jun. 2004, DOI: 10.1007/s00421-004-1055-z.

[110] K. A. Matthews, C. R. Katholi, H. McCreath, M. A. Whooley, D. R. Williams, S. Zhu, J. H. Markovitz, "Blood pressure reactivity to psychological stress predicts hypertension in the CARDIA study," Circulation, vol. 110, no. 1, pp. 74-78, Jul. 2004, DOI: 10.1161/01.cir.0000133415.37578.e4.

[111] P. A. Obrist, C. J. Gaebelein, E. S. Teller, A. W. Langer, A. Grignolo, K. C. Light, and J. A. McCubbin, "The relationship among heart rate, carotid $\mathrm{dP} / \mathrm{dt}$, and blood pressure in humans as a function of the type of stress," Psychophysiology, vol. 15, no. 2, pp. 102-115, 1978, DOI: 10.1111/j.1469-8986.1978.tb01344.x.

[112] F. Kobayashi, T. Watanabe, M. Watanabe, Y. Akamatsu, T. Tomita, T. Nakane, H. Furui, K. Takeuchi, A. Okada, R. Ohashi, and J. Hayano, "Blood pressure and heart rate variability in taxi drivers on long duty schedules," J. Occup. Health, vol. 44, no. 4, pp. 214-220, Jul. 2002, DOI: 10.1539/joh.44.214.

[113] Q. Ji, Z. Zhu, and P. Lan, "Real-time nonintrusive monitoring and prediction of driver fatigue," IEEE Trans. Veh. Technol., vol. 53, no. 4, pp. 1052-1068, Jul. 2004, DOI: 10.1109/tvt.2004.830974.

[114] S. A. Khan, S. Hussain, X. Sun, and S. Yang, "An Effective Framework for Driver Fatigue Recognition Based on Intelligent Facial Expressions Analysis," Ieee Access, vol. 6, pp. 67459-67468, 2018, DOI: 10.1109/access.2018.2878601.

[115] V. K. Reddy and K. S. Swathi, "Investigation of effectiveness of simple thresholding for accurate yawn detection," in Adv. Intell. Syst. Comput., vol. 553, 2017, pp. 81-89.

[116] N. Alioua, A. Amine, and M. Rziza, "Driver's fatigue detection based on yawning extraction,” Int. J. Veh. Technol., vol. 2014, pp. 1-7, 2014, Art. no. 678786, DOI: 10.1155/2014/678786.

[117] L. M. Bergasa, J. Nuevo, M. A. Sotelo, R. Barea, and M. E. Lopez, "Real-time system for monitoring driver vigilance," IEEE Trans. Intell. Transp. Syst., vol. 7, no. 1, pp. 63-77, Mar. 2006, DOI: 10.1109/tits.2006.869598.

[118] T. Oron-Gilad and A. Ronen, "Road characteristics and driver fatigue: A simulator study," Traffic Inj. Prev., vol. 8, no. 3, pp. 281-289, Sep. 2007, DOI: 10.1080/15389580701354318.

[119] F. Friedrichs and B. Yang, "Camera-based Drowsiness Reference for Driver State Classification under Real Driving Conditions," in Proc. 2010 IEEE Intell. Veh. Symp. (IV), San Diego, CA, USA, Jun. 2010, pp. 101-106.

[120] A. Mitas, M. Bugdol, and A. Rygula, "Simultaneous analysis of driver's physiological and behavioural parameters under the aspect of transport safety," J. Med. Inform. Technol., vol. 13/2009, 2009.

[121] D. Krauss, Forensic aspects of driver perception and response, 4 ed. Lawyers \& Judges Publishing, 2015.

[122] E. Pfleger and C. Jechlinger, "Disclosure of the Differences in the Navigation and Viewing Behaviour at day and Night with viewpoint system Viewing Analysis based on real Examples," in Proc. 2010 EVU Congr., 2010, pp. 59-66.

[123] E. Pfleger and M. Hohenbuechler, "Viewing analyses of riders of electrically powered bicycles and segways in conflicts with other road users," Verkehrsunfall und Fahrzeugtechnik, vol. 50, no. 4, 2012.

[124] R. Kledus, M. Semela, P. Maxera, M. Kunovský, and M. Křižák, "Driver's behavior while passing through pedestrian crossing analysis," presented at the Expert FOrensic Science (ExFoS) 2013, Brno, Czech Republic, 2013.

[125] K. H. Sanjaya, K. A. Damayanti, and N. Hadi, "The Comparison between Pre-and Post-Lunch Driving Performance among Morning Person Subjects during a Simulated Driving," in Proc. 2018 6th Int. Conf. Sustainable Energy Eng. and Application (ICSEEA), Tangerang, Indonesia, Nov. 2018, pp. 7-13. 
[126] R. J. Hanowski, D. Bowman, A. Alden, W. W. Wierwille, and R. Carroll, "Perclos+: Development of a robust field measure of driver drowsiness," in Proc. 15th World Congr. Intell. Transp. Syst. and ITS Am. Annu. Meeting 2008, New York, NY, USA Nov. 2008, pp. 47834794.

[127] P. Zheng and C. Q. Zhang, "Hardware design of fatigue detection system based on PERCLOS," in Proc. 3rd Int. Conf. Multimedia Inform. Netw. Security (MINES), Shanghai, China, Nov. 2011, pp. 1-5

[128] A. Williamson and T. Chamberlain, "Review of on-road driver fatigue monitoring devices," University of New South Wales, pp. 43-52, Jan. 2005.

[129] W. Liao, W. Zhang, Z. Zhu, and Q. Ji, "A Real-Time Human Stress Monitoring System Using Dynamic Bayesian Network," in 2005 IEEE Comput. Soc. Conf. Comput. Vision Pattern Recognition (CVPR'05) Workshops, San Diego, CA, USA, Sept. 2005, pp. 70-70.

[130] S. K. Lal and A. Craig, "A critical review of the psychophysiology of driver fatigue," Biol. Psychol., vol. 55, no. 3, pp. 173-194, Feb. 2001, DOI: 10.1016/s0301-0511(00)00085-5.

[131] M. Rimini-Doering, D. Manstetten, T. Altmueller, U. Ladstaetter, and M. Mahler, "Monitoring Driver Drowsiness and Stress in a Driving Simulator," in Proc. 1st Int. Driving Symp. Hum. Factors Driver Assess. Train. Veh. Des., Aspen, CO, USA, Aug. 2001, pp. 58-63.

[132] J. F. May and C. L. Baldwin, "Driver fatigue: The importance of identifying causal factors of fatigue when considering detection and countermeasure technologies," Transp. Res. Pt. F-Traffic Psychol. Behav., vol. 12, no. 3, pp. 218-224, May 2009, DOI: 10.1016/j.trf.2008.11.005.

[133] A. Bradáč, Soudní inženýrství, 1 ed. Akademické nakladatelství CERM, 1997.

[134] H. J. Eoh, M. K. Chung, and S.-H. Kim, "Electroencephalographic study of drowsiness in simulated driving with sleep deprivation," Int. J. Ind. Ergon., vol. 35, no. 4, pp. 307-320, Apr. 2005, DOI: 10.1016/j.ergon.2004.09.006

[135] C. D. Katsis, N. E. Ntouvas, C. G. Bafas, and D. I. Fotiadis, "Assessment of muscle fatigue during driving using surface EMG," in Proc. $2^{\text {nd }}$ IASTED Int. Conf. Biomed. Eng., Jan. 2014, pp. 259-262.

[136] D. V. McGehee and O. M. Carsten, "Perception and biodynamics in unalerted precrash response," in Ann. Adv. Automot. Med., 2010, pp. 315-332.

[137] K. Bucsuházy, V. Svozilová, O. Vallová, M. Semela, J. Sekora, M. Belák, P. Maxera, and R. Kledus, "Analysis of driver reaction time using the acquisition of biosignals," in Proc. 3rd Int. Conf. Traffic Transp. Eng. (ICTTE), Nov. 2016, pp. 68-74.

[138] T. Kakizaki, T. Oka, and S. Kurimori, "Changes in mental workload and fatigue during performance of a mental task: 1. An Experiment in 8-h Self-Paced Transcribing Task," Sangyo Igaku, vol. 34, no. 6, pp. 565573, Nov. 1992, DOI: 10.1539/joh1959.34.565.

[139] T. Yamakoshi, K. Yamakoshi, S. Tanaka, M. Nogawa, M. Shibata, Y. Sawada, P. Rolfe, Y. Hirose, "A preliminary study on driver's stress index using a new method based on differential skin temperature measurement," in Conf Proc. IEEE Eng. Med. Biol. Soc. (EMBS), Lyon, France, Aug. 2007, pp. 722-725.

[140] T. Yamakoshi, K. Yamakoshi, S. Tanaka, M. Nogawa, S. B. Park, M Shibata, Y. Sawada, P. Rolfe, Y. Hirose, "Feasibility study on driver's stress detection from differential skin temperature measurement," in Conf Proc. IEEE Eng. Med. Biol. Soc. (EMBS), Vancouver, BC, Canada, Aug. 2008, pp. 1076-1079.

[141] G. Yang, Y. Lin, and P. Bhattacharya, "A driver fatigue recognition model based on information fusion and dynamic Bayesian network," Inf. Sci., vol. 180, no. 10, pp. 1942-1954, May 2010, DOI: 10.1016/j.ins.2010.01.011.

[142] L.-I. Chen, A. Zhang, and X.-G. Lou, "Cross-subject driver status detection from physiological signals based on hybrid feature selection and transfer learning," Expert Syst. Appl., 2019, DOI: 10.1016/j.eswa.2019.02.005

[143] C. J. de Naurois, C. Bourdin, A. Stratulat, E. Diaz, and J.-L. Vercher, "Detection and prediction of driver drowsiness using artificial neural network models," Accid. Anal. Prev., vol. 126, pp. 95-104, 2019, DOI: 10.1016/j.aap.2017.11.038.

[144] H. Zeng, C. Yang, G. Dai, F. Qin, J. Zhang, and W. Kong, "EEG classification of driver mental states by deep learning," Cogn. Neurodynamics, vol. 12, no. 6, pp. 597-606, Dec. 2018, DOI: 10.1007/s11571-018-9496-y.

[145] B. Verma and A. Choudhary, "A Framework for Driver Emotion Recognition using Deep Learning and Grassmann Manifolds," in Proc. 21st Int. IEEE Conf. Intell. Transp. Syst. (ITSC), Maui, HI, USA, Nov. 2018, pp. 1421-1426.

[146] Y. Zhang, Y. Chen, and Z. Pan, “A Deep Temporal Model for Mental Fatigue Detection," in Proc. IEEE Int. Conf. Syst. Man Cybern. (SMC), Oct. 2018, pp. 1879-1884

[147] Q. C. Ihemedu-Steinke, R. Erbach, P. Halady, G. Meixner, and M. Weber, "Virtual Reality Driving Simulator Based on Head-Mounted Displays," in Automot. User Interfaces, 2017, pp. 401-428.

[148] Tobii, "Tobii VR." [online]. Available: https://vr.tobii.com/. Accessed on Mar. 29, 2019.

[149] J. O. Brooks, R. R. Goodenough, M. C. Crisler, N. D. Klein, R. L. Alley, B. L. Koon, W. C. Logan, Jr., J. H. Ogle, R. A. Tyrrell, R. F. Wills, "Simulator sickness during driving simulation studies," Accid. Anal. Prev., vol. 42, no. 3, pp. 788-796, May 2010, DOI: 10.1016/j.aap.2009.04.013.

[150] G. Matthews, D. J. Saxby, G. J. Funke, A. K. Emo, and P. A. Desmond, "Driving in states of fatigue or stress," in Handbook of Driving Simulation for Engineering, Medicine, and Psychology, CRC Press, 2011, pp. 29-1-29-12.

[151] D. J. Saxby, G. Matthews, E. M. Hitchcock, J. S. Warm, G. J. Funke, and T. Gantzer, "Effect of active and passive fatigue on performance using a driving simulator," in Proc. Hum. Factors Ergon. Soc., Sep. 2008, pp. 1751-1755.

[152] D. J. Saxby, G. Matthews, J. S. Warm, E. M. Hitchcock, and C. Neubauer, "Active and passive fatigue in simulated driving: Discriminating styles of workload regulation and their safety impacts," J. Exp. Psychol. Appl., vol. 19, no. 4, pp. 287-300, Dec. 2013, DOI: 10.1037/a0034386.

[153] P. Philip, P. Sagaspe, J. Taillard, C. Valtat, N. Moore, T. Akerstedt, A. Charles, B. Bioulac, "Fatigue, sleepiness, and performance in simulated versus real driving conditions," Sleep, vol. 28, no. 12, pp. 1511-1516, Dec 2005, DOI: 10.1093/sleep/28.12.1511.

[154] P. A. Desmond and G. Matthews, "Implications of task-induced fatigue effects for in-vehicle countermeasures to driver fatigue," Accid. Anal. Prev., vol. 29, no. 4, pp. 515-523, Jul 1997, DOI: 10.1016/s00014575(97)00031-6.

[155] G. Matthews and P. A. Desmond, "Task-induced fatigue states and simulated driving performance," Q. J. Exp. Psychol. A., vol. 55, no. 2, pp. 659-686, Apr. 2002, DOI: 10.1080/02724980143000405.

[156] Loeber Motors, "How Does Mercedes-Benz Attention Assist Work?" [online]. Available: https://www.loebermotors.com/blog/how-doesmercedes-benz-attention-assist-work/. Accessed on Jan. 10, 2019.

[157] Daimler, "Attention assist: Drowsiness-detection system warns drivers to prevent them falling asleep momentarily." [online]. Available: https://media.daimler.com/marsMediaSite/ko/en/9361586. Accessed Feb. 14, 2019

[158] XC60 web edition owner's manual, Volvo, Sweden, 2015. [Online]. Available:

https://az685612.vo.msecnd.net/pdfs/e018a3f96d804ea5f88e48d40c10 64a6ffe82fc4/XC60_OwnersManual_MY16_US_tp18910.pdf.

[159] Ford, "What are the Ford Driver Alert and Lane Keeping Aids?" [online]. Available: https://www.tch.co.uk/about/why-chooseford/lane-keeping-aid/. Accessed Feb. 25, 2019.

[160] Volkswagen, "Take a break!" [online]. Available: http://inside.volkswagen.com/Take-a-break.html. Accessed Jan. 17, 2019.

[161] Toyota, "Toyota Enhances Pre-crash Safety System with Eye Monitor." [online]. Available: https://global.toyota/en/detail/281564. Accessed Jan. 17, 2019.

[162] T. Zhang, A. H. S. Chan, H. Xue, X. Zhang, and D. Tao, "Driving anger, aberrant driving behaviors, and road crash risk: testing of a mediated model," Int. J. Environ. Res. Public Health, vol. 16, no. 3, pp. 1-13, DOI: 10.3390/ijerph16030297.

[163] S. Useche, A. Serge, and F. Alonso, "Risky behaviors and stress indicators between novice and experienced drivers," Am. J. Appl. Psychol., vol. 3, no. 1, pp.11-14, 2015, DOI: 10.12691/ajap-3-1-3.

[164] G. Rigas, Y. Goletsis, P. Bougia, and D. I. Fotiadis, "Towards Driver's State Recognition on Real Driving Conditions," Int. J. Veh. Technol., vol. 2011, pp. 1-14, 2011, Art. no. 617210, DOI: 10.1155/2011/617210.

[165] P. Philip, P. Sagaspe, J. Taillard, C. Valtat, N. Moore, T. Akerstedt, A. Charles, and B. Bioulac, "Fatigue, sleepiness, and performance in simulated versus real driving conditions," Sleep, vol. 28, no. 12, pp. 1511-1516, Dec. 2005, DOI: 10.1093/sleep/28.12.1511.

[166] P. A. Hancock, I. Nourbakhsh and J. Stewart, "On the future of transportation in an era of automated and autonomous vehicles," Proc. 
Natl. Acad. Sci. U. S. A., vol. 116, no. 16, pp. 7684-7691, Apr. 2019, DOI: $10.1073 /$ pnas. 1805770115 .

[167] P. Koopman and M. Wagner, "Autonomous Vehicle Safety: An Interdisciplinary Challenge," IEEE Intell. Transp. Syst. Mag., vol. 9, no. 1, 2017, DOI: 10.1109/MITS.2016.2583491.

[168] NHTSA (National Highway Traffic Safety Administration), "Preliminary statement of policy concerning automated vehicles," 2013. [Online]. Available: https://www.nhtsa.gov/staticfiles/rulemaking/ pdf/Automated_Vehicles_Policy.pdf.

[169] M. Jabon, J. Bailenson, E. Pontikakis, L. Takayama, and C. Nass, "Facial expression analysis for predicting unsafe driving behavior," IEEE Pervas. Comput., vol. 10, no. 4, Apr. 2011, DOI: 10.1109/MPRV.2010.46.

[170] H. Gao, A. Yüce, and J.-P. Thiran, "Detecting emotional stress from facial expressions for driving safety," in Proc. Int. Conf. Image Process (ICIP), Paris, France, Oct. 2014, pp. 5961-5965.

[171] M. Jeong and B. C. Ko, "Driver's Facial Expression Recognition in Real-Time for Safe Driving," Sensors, vol. 18, no. 12, Art. no. 4270, Dec. 2018, DOI: 10.3390/s18124270.

[172] N. Rodríguez-Ibáñez, M. A. García-González, M. Fernández-Chimeno, and J. Ramos-Castro, "Drowsiness detection by thoracic effort signal analysis in real driving environments," in Conf. Proc. IEEE Eng. Med. Biol. Soc., Boston, MA, USA, Aug.-Sep. 2011, pp. 6055-6058.

[173] E. Bekiaris, K. Wevers, and A. Admitis, "Advanced driver monitoring - the AWAKE project", in Proc. 8th World Congr. Intell. Transp. Syst., Sydney, Australia, Sep.-Oct. 2001.

[174] H. Ueno, M. Kaneda, and M. Tsukino, "Development of drowsiness detection system", in Proc. Veh. Navig. Inform. Syst. Conf. (VNIS), Yokohama, Japan, Aug.-Sep. 1994.

[175] S. Panda and M. Kolhekar, "Feature selection for driver drowsiness detection," in Proc. Int. Conf. Comput. Intell. Data Eng. (ICCIDE), Vadlamudi, India, Sep. 2018, pp. 127-140.

[176] C. Schwarz, J. Gaspar, T. Miller, and R. Yousefian, "The detection of drowsiness using a driver monitoring system," Traffic Inj. Prev., vol 20, no. S1, pp. S157-S161, 2019, DOI: 10.1080/15389588.2019.1622005.

[177] A. D. McDonald, C. Schwarz, J. D. Lee, and T. L. Brown, "Real-time detection of drowsiness related lane departures using steering wheel angle," in Proc Hum. Factors Ergon. Soc Annu. Meet. (HFES), Boston, MA, USA, vol. 56, no. 1, pp. 2201-2205, 2012.

[178] A, Heitmann, R. Guttkuhn, A. Aguirre, U. Trutschel, and M. MooreEde, "Technologies for the monitoring and prevention of driver fatigue," in Proc. Int. Driving Symp. Hum. Factors in Driver Assess. Train. Veh. Des., Aspen, IA, USA, Aug. 2001, pp. 81-86.

[179] J. C. McCall and M. M. Trivedi, "Visual context capture and analysis for driver attention monitoring," in Proc. 7th Int. IEEE Conf. Intell. Transp. Syst. (ITSC), Washington, USA, Oct. 2004, pp. 332-337.

[180] A. Dasgupta, A. George, S. L. Happy, and A. Routray, "A vision-based system for monitoring the loss of attention in automotive drivers," IEEE Trans. Intell. Transp. Syst., vol. 14, no. 4, pp. 1825-1838, Dec. 2013, DOI: 10.1109/TITS.2013.2271052.

[181] P. J. Legree, T. S. Heffner, J. Psotka, D. E. Martin, and G. J. Medsker, "Traffic crash involvement: Experiential driving knowledge and stressful contextual antecedents," J. Appl. Psychol., vol. 88, no. 1, pp. 15-26, Feb. 2003, DOI: 10.1037/0021-9010.88.1.15.

[182] L. McMurray, "Emotional stress and driving performance: The effect of divorce," Behav. Res. Highway Safety, vol. 1, no. 2, pp. 100-114, 1970.

[183] E. Lagarde, J. F. Chastang, A. Gueguen, M. Coeuret-Pellicer, M. Chiron, and S. Lafont, "Emotional stress and traffic accidents: the impact of separation and divorce," Epidemiology, vol. 15, no. 6, pp. 762-766, Nov. 2004.

[184] M. L. Selzer and A. Vinokur, "Role of life events in accident causation," Mental Health Soc., vol. 2, no. 1-2, pp. 36-54, 1975.

[185] Z. Chen, C. Wu, M. Zhong, N. Lyu, and Z. Huang "Identification of common features of vehicle motion under drowsy/distracted driving: A case study in Wuhan, China," Accid. Anal. Prev., vol. 81, pp. 251-259, Aug. 2015.

[186] Z. Li, L. Chen, J. Peng, and Y. Wu, "Automatic detection of driver fatigue using driving operation information for transportation safety," Sensors, vol. 17, no. 6, Art. no. 1212, May 2017, DOI: 10.3390/s17061212.

[187] A. Campagne, T. Pebayle, and A. Muzet, "Correlation between driving errors and vigilance level: influence of the driver's age," Physiol. Behav., vol. 80, no. 4, pp. 515-524, Jan. 2004, DOI:10.1016/j.physbeh.2003.10.004
[188] D. A. Attwood and P. L. Scott, "The on-line use of performance measures to predict driver fatigue," in Proc Hum. Factors Ergon. Soc Annu. Meet. (HFES), vol. 25, no. 1, pp. 726-730, 1981.

[189] T. A. Dingus, "Development of models for detection of automobile driver impairment," Ph.D. dissertation, Virginia Tech, Blacksburg, VA, USA, 1985.

[190] Z. Li, S. E. Li, R. Li, B. Cheng, and J. Shi, "Online detection of driver fatigue using steering wheel angles for real driving conditions," Sensors, vol. 17, no. 3, Art. no. 495, March 2017, DOI: 10.3390/s17030495.

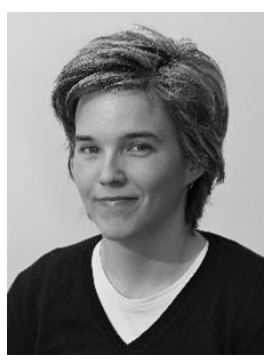

Andrea Němcová received her MSc degree in Biomedical Engineering and Bioinformatics in 2014 from the Brno University of Technology (BUT), Czech Republic. She is a PhD student and researcher at BUT. Her research interests involve biosignal analysis, telemedicine, health monitoring using smart devices, and driver stress and fatigue detection.

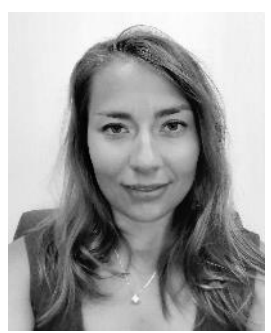

Veronika Svozilová received her MSc degree in Biomedical engineering from Brno University of Technology (BUT) in 2015. She is a PhD student and researcher at BUT. Her current research interests involve biosignal acquisition and processing within transport and traffic, driver fatigue and gait analysis.

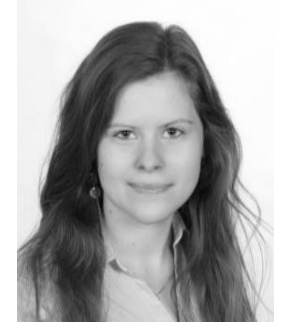

Kateřina Bucsuházy received her MSc degree in Expert engineering in transport and Biomedical engineering from Brno University of Technology (BUT). She is a $\mathrm{PhD}$ student and researcher at the BUT and Transport Research Centre. Her professional activity is focused on the accident analysis and prevention and involve road safety and driver behavior analysis. She has been part of in-depth crash investigation team in the Czech Republic.

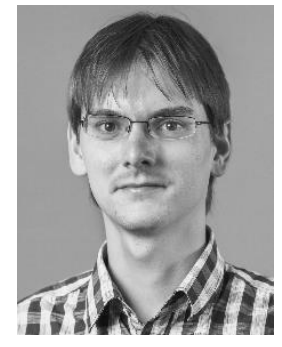

Radovan Smíšek received his MSc degree in biomedical engineering from Brno University of Technology (BUT) in 2015. $\mathrm{He}$ is a PhD student and researcher at BUT. His current research interests involve automatic detection of fatigue and stress, detection and therapy of heart pathology, and automatic analysis of biosignals, especially ECG.

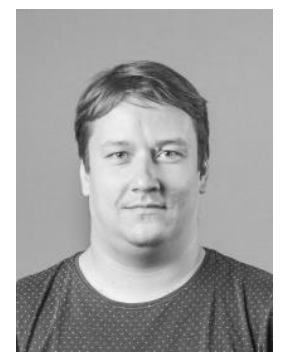

Martin Mézl received his $\mathrm{PhD}$ degree in biomedical engineering from Brno University of Technology in 2017. He has been teaching and research assistant with the Department of Biomedical Engineering since 2012. His research interests involve physics of medical imaging, signal and image processing in perfusion imaging and driver stress detection. 


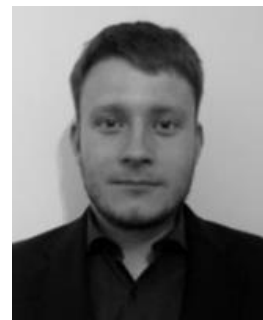

Branislav Hesko received her MSc degree in Biomedical and ecological engineering from Brno University of Technology (BUT) in 2015 and MSc degree in plasma physics from Masaryk University in 2018. $\mathrm{He}$ is currently a $\mathrm{PhD}$ student and researcher at BUT. His current research interests involve computer vision in medical diagnostics, deep learning and signal processing.

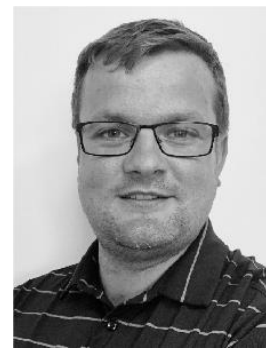

Martin Bilík received his $\mathrm{PhD}$ degree in forensic engineering from Brno University of Technology (BUT) in 2019. Since 2018, he has been an Assistant Professor with the Department of Expertise in Mechanical Engineering, Analysis of Traffic Accidents and Vehicle Assessment IFE BUT. His research interests involve detection of invisible tire traces in traffic accident place.

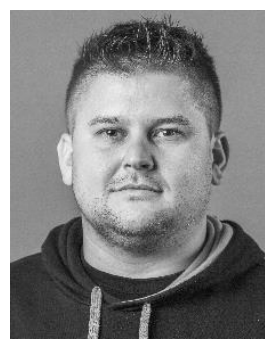

Michal Belák received his MSc degree in Expert engineering in transport from Brno University of Technology (BUT). He is a $\mathrm{PhD}$ student, researcher and since 2015 , he has been a researcher at Institute of Forensic Engineering of BUT. His professional activity is focused on the accident analysis and prevention. His current research interests involve road safety and analysis of driver's behavior.

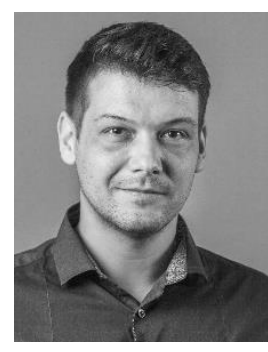

Pavel Maxera received his MSc degree in Expert engineering in transport from Brno University of Technology (BUT) in 2012. $\mathrm{He}$ is a PhD student and researcher at BUT. His research interests involve analysis of drivers conduct at pedestrian crossings by using eyetracking method, optical reactions of drivers and influence of them in these driving situations.

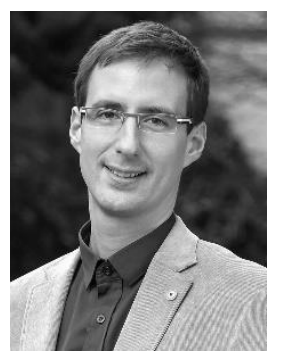

Martin Seitl was born in Brno, Czech Republic, in 1981. He received a Ph.D. degree in pedagogical psychology from Palacký University in Olomouc, in 2012. Since 2012, he has been an Assistant Professor with the Department of Psychology, Faculty of Arts, Palacký University in Olomouc. His research interests include personality assessment; development of psychodiagnostic methods; the interaction of individuals with workplace, organization and traffic system; and prediction of the behavior of individuals and groups at the workplace.

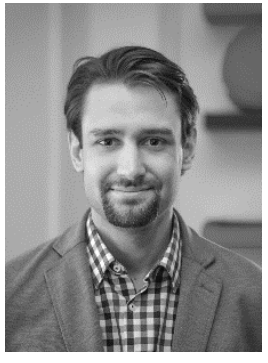

Tomáš Dominik received his Master degree in Psychology from the Department of Psychology at Palacký University Olomouc. He is currently a PhD student of clinical psychology. His interests are cognitive science and psychophysiology, especially in the field of volition.

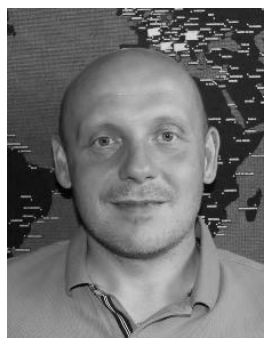

Marek Semela received his MSc degree in Mechanical Engineering from Brno University of Technology (BUT) and Faculty of Law of Masaryk University in Brno and received his $\mathrm{PhD}$ degree in Forensic Engineering from BUT. Since 2010 he has been fellow and since 2019 an Associate Professor at the Institute of Forensic Engineering of BUT. His research interests involve road traffic accident analysis including prevention, road safety, vehicle dynamics and traffic law.

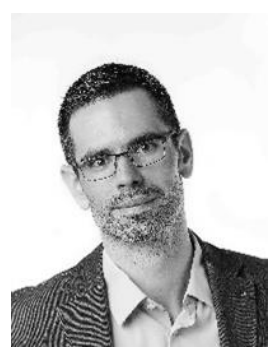

Matúš Šucha specializes in traffic psychology, the human factor in traffic in general, and on management consulting. His research focuses on traffic psychology, traffic safety, and especially on vulnerable road users. $\mathrm{He}$ is an accredited coach, traffic psychologist, psychotherapist, an EuroPsy mentor in traffic psychology and court expert in the field of traffic psychology. He is currently working at the Psychology department of Palacký University in Olomouc and International Traffic psychology working group lead by Professor Ralf Risser, based in Vienna, Austria.

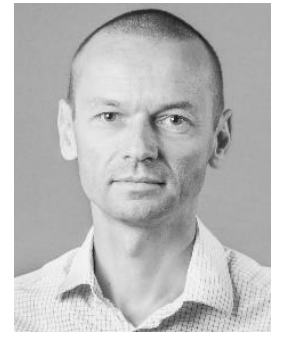

Radim Kolář received his $\mathrm{PhD}$ degree in biomedical engineering from Brno University of Technology (BUT) in 2002. Since 2009, he has been an Assistant Professor with the Department of Biomedical Engineering, BUT. His current research interests involve signal and image analysis in different applications, particularly in ophthalmology and automotive, involving machined learning approaches. 